\title{
Photoluminescence of Eu(III) Doped Double Perovskite Phosphor for Red LED Application
}

\section{VISHWNATH VERMA ( $\nabla$ vermavicky.1988@gmail.com )}

THE M.S.UNIVERSITY OF BARODA https://orcid.org/0000-0001-6174-7034

\section{Nimesh P. Patel}

The Maharaja Sayajirao University of Baroda Faculty of Science

\section{K.V.R. Murthy}

The Maharaja Sayajirao University of Baroda Faculty of Technology and Engineering

\section{Srinivas}

The Maharaja Sayajirao University of Baroda Faculty of Science

\section{Research Article}

Keywords: Double Perovskite, XRD, FTIR, Photoluminescence

Posted Date: February 10th, 2021

DOl: https://doi.org/10.21203/rs.3.rs-210949/v1

License: (9) This work is licensed under a Creative Commons Attribution 4.0 International License. Read Full License 


\title{
Photoluminescence of Eu(III) doped Double Perovskite Phosphor for Red LED Application
}

\author{
Vishwnatha R. Verma*a, Nimesh P. Patel a, K.V.R. Murthy ${ }^{\text {b }}{ }^{*}$ M.Srinivas ${ }^{a}$ \\ ${ }^{a}$ Luminescence materials Lab, Department of Physics, Faculty of Science, The M. S. University of Baroda, Vadodara - \\ 390002, Gujarat, India. \\ ${ }^{\mathrm{b}}$ Display Materials Laboratory, Applied Physics Department, Faculty of Technology and Engineering, The M. S. University \\ of Baroda, Vadodara - 390001, Gujarat, India. \\ Email ID: vermavicky.1988@gmail.com
}

\begin{abstract}
The luminescence property of $\mathrm{Ba}_{2} \mathrm{CeNbO}_{6}$ has been studying by varying $\mathrm{Eu}(\mathrm{III})$ concentration. $\mathrm{Ba}_{2} \mathrm{CeNbO}_{6}$ doped with trivalent ions of Eu has a monoclinic phase with $\mathrm{P} 2_{1} / \mathrm{n}$ space group. FTIR of $\mathrm{Ba}_{2} \mathrm{CeNbO}_{6}$ gives information that phosphor has a nano-size perovskite structure with an edgeconnected $\mathrm{Nb}-\mathrm{O}$ octahedral. Photoluminescence properties of $\mathrm{Eu}(\mathrm{III})$ doped $\mathrm{Ba}_{2} \mathrm{CeNbO}_{6}$ have been examined with excitation wavelength $275 \mathrm{~nm}$ and $466 \mathrm{~nm}$. Luminescence emission spectra exhibited three prominent peaks around $580 \mathrm{~nm}, 596 \mathrm{~nm}$, and 610nm wavelength for Eu(III). Using xenon lamp as a source and having excitation wavelength 275 and $466 \mathrm{~nm}$, observing that the maximum light emission yielded in the region presenting a color-correlated temperature in the range of $1500-2900$ $\mathrm{K}$.
\end{abstract}

Keywords Double Perovskite; XRD; FTIR; Photoluminescence

\section{INTRODUCTION}

The $\mathrm{A}_{2} \mathrm{BB}^{\prime} \mathrm{O}_{6}$ type double perovskite structure has a vital interest to materials scientists and solid-state chemists. This attention is often due to their potential application as substrates for high-Tc superconductors, especially for applications in the microwave region [1 - 5]. Double perovskite-type oxides are suitable for such purposes due to their outstanding dielectric properties, including a low dielectric loss, low chemical reactivity, and their compatibility with some of the most regularly used superconductors, particularly as a result of owning an appropriate thermal expansion co-efficient. They are concern as they give a material where the magnetic properties of lanthanides studied in a relatively significant octahedral environment [6 - 10] and have been recently reviewed for their potential use as luminescent materials [11].

Perovskite is a new derivative of a close-packed structure in which the oxygen arranged in a cubic close-packed organization except one oxygen ion is missing in every second layer, leaving a large volume void in the center. The strength of perovskite to accommodate large cations of rare earth elements makes it novel among the close-packed oxides. If the 12-coordinated cation is smaller compared to the oxide ion, the tilting of 
octahedra changes the perovskite structure [12]. The modified structure produced after tilting could be tetragonal, orthorhombic, monoclinic, or sometimes without any center of symmetry. Non-centric perovskites display piezoelectricity or ferroelectricity, and synthetic perovskites used as electronic sensors. The structure of the newly discovered hightemperature superconductor shows resemblance with perovskite structure [13].

Around $90 \%$ of the natural metallic elements of the periodic table are known to be stable in a perovskite-type oxide structure. Perovskites have sub-metallic to metallic luster, colorless streak, cube-like structure along with imperfect cleavage, and brittle tenacity. Perovskites can be prepared in various forms like nanocrystalline, bulk, thin films, and rods depending on their applications [14].

It's well known that the complex oxides having perovskite-type structure usually show functional properties $[15,16]$. Among them, the researcher paid attention to the $\mathrm{Ba}_{2} \mathrm{LnNbO}_{6}$ ( $\mathrm{Ln}=$ lanthanide elements) compounds. $\mathrm{Ba}_{2} \mathrm{LnNbO}_{6}$ type perovskite compound was first synthesized by Brixner [15] and found to have a cubic perovskite-type structure for all except for $\mathrm{Ln}=\mathrm{La}$, which is tetragonally distorted structure, and some of them have ferroelectric properties. Later, Filip'ev et al. [17] reported that the structure of $\mathrm{Ln}=\mathrm{La}$ had a rhombohedral distorted structure. Anderson et al. [18], however, point out that the crystal system of $\mathrm{A}_{2} \mathrm{BB}^{\prime} \mathrm{O}_{6}$ double perovskites is cubic, orthorhombic, or monoclinic because the $\mathrm{B} / \mathrm{B}^{\prime}$-cation arrangement is limited to be a random type, a rock salt type, or a layered type. When the $\mathrm{B} / \mathrm{B}^{\prime}$ - cation arrangement is a rock salt type, the crystal system should be either a cubic one $(F m \overline{3} m)[19,20]$ or a monoclinic one $\left(\mathrm{P} 2_{1} / \mathrm{n}\right)$ [21, 22], for random type arrangement, the crystal system should be either a cubic one $(\operatorname{Pm} \overline{3} m)$ [20, 23] or a orthorhombic one (Pbnm) $[21,24]$ and for layered type, the crystal system should be monoclinic one (P2 $1 / n)$ [25].

Practically all kinds of optical centres were studied in the perovskite structure for various doped concentrations. The studies of optical properties of perovskite systems have contributed considerably to the development of many optical materials like LASER materials, solar energy conversion and many more [26, 27].

There is no reported data were found on photoluminescence properties of rare earth doped $\mathrm{Ba}_{2} \mathrm{CeNbO}_{6}$ during the literature survey. Our group report the photoluminescence studies of $\mathrm{Ba}_{2} \mathrm{CeNbO}_{6}$ doped with $\mathrm{Eu}$ (III). 


\section{SYNTHESIS AND CHARACTERIZATION}

\subsection{SYNTHESIS}

$\mathrm{Eu}(\mathrm{III})$ doped $\mathrm{Ba}_{2} \mathrm{CeNbO}_{6}$ phosphor had been synthesized by the combustion method. Starting chemicals used for this objective are $\mathrm{Ba}\left(\mathrm{NO}_{3}\right)_{2}, \mathrm{Ce}\left(\mathrm{NO}_{3}\right)_{3} .6 \mathrm{H}_{2} \mathrm{O}, \mathrm{Nb}_{2} \mathrm{O}_{5}, \mathrm{Eu}_{2} \mathrm{O}_{3}$, and urea as flux. These chemicals were intimately mixed in the stoichiometric ratio corresponding to the nominal composition of $\mathrm{Eu}(\mathrm{III})$ doped $\mathrm{Ba}_{2} \mathrm{CeNbO}_{6}$ and transferred into alumina crucible. Then, this mixture was fired at $800^{\circ} \mathrm{C}$ in a muffle furnace for 3 hours and then allowed it naturally cool to room temperature. The synthesized material ground using mortar - pastel was obtained in powder form owning white color.

\subsection{CHARACTERIZATION}

XRD measurements of undoped and $\mathrm{Eu}(\mathrm{III})$ doped $\mathrm{Ba}_{2} \mathrm{CeNbO}_{6}$, were done on D8 Bruker advance $\mathrm{X}$-Ray Diffractometer with the $\mathrm{Cu} \mathrm{K \alpha}$ radiation with $8.05 \mathrm{keV}$ energy, and $1.5406 \AA$ wavelength $(\lambda)$ at room temperature by step scanning in an angle range of $20^{\circ} \leq 2 \theta$ $\leq 70^{\circ}$ with increments of $0.02^{\circ}$. FTIR spectra of phosphors were, recorded using Jasco FTIR4100, spectrophotometer (Japan) by mixing phosphor with $\mathrm{KBr}$ in mortar - pestle in a ratio of 1:10. The PL of the samples examined using a Shimadzu spectrofluorophotometer (RF-5301 PC) at room temperature with a xenon lamp as an excitation source.

\section{RESULTS AND DISCUSSION}

\subsection{X-RAY DIFFRACTION}

Figure 1 exhibits room-temperature powder X-ray diffraction pattern of undoped, and $\mathrm{Eu}(\mathrm{III})$ doped $\mathrm{Ba}_{2} \mathrm{CeNbO}_{6}$. The recorded patterns present sharp and well-defined peaks, indicating that prepared materials have a highly crystalline nature. There is a good agreement between the observed and calculated inter-planar spacing suggests that the compound has a monoclinic phase with a $\mathrm{P} 21 / \mathrm{n}$ (\#14) space group. The relative coordinates and occupancy of each site for $\mathrm{Ba}_{2} \mathrm{CeNbO}_{6}$ are listed in Table 1. The values of bond distances of cations relative to the oxygen anion and occupancy were obtained from the Rietveld refinement are shown in Table 2. These diffraction lines are consistent and confirm the formation of a double perovskite structure for all prepared samples. The average crystalline size were estimated by the Scherrer's equation using the full width at half maximum (FWHM) of all 
intense peak. The average crystalline size was calculated using the Debye-Scherrer formula [28] which is given as equation (1),

$$
D=\frac{k \cdot \lambda}{\beta \cdot \cos \theta}
$$

Where, $\mathrm{D}$ is the average crystalline size, $\mathrm{k}$ is the constant equal to $0.94, \lambda$ is the wavelength of the $\mathrm{X}$-rays equal to $0.1542 \mathrm{~nm}, \theta$ is the Bragg angle and $\beta$ is FWHM. All the reflection peaks of the X-ray profile indexed and lattice parameters are determined with the help of a standard computer program Powder-X.

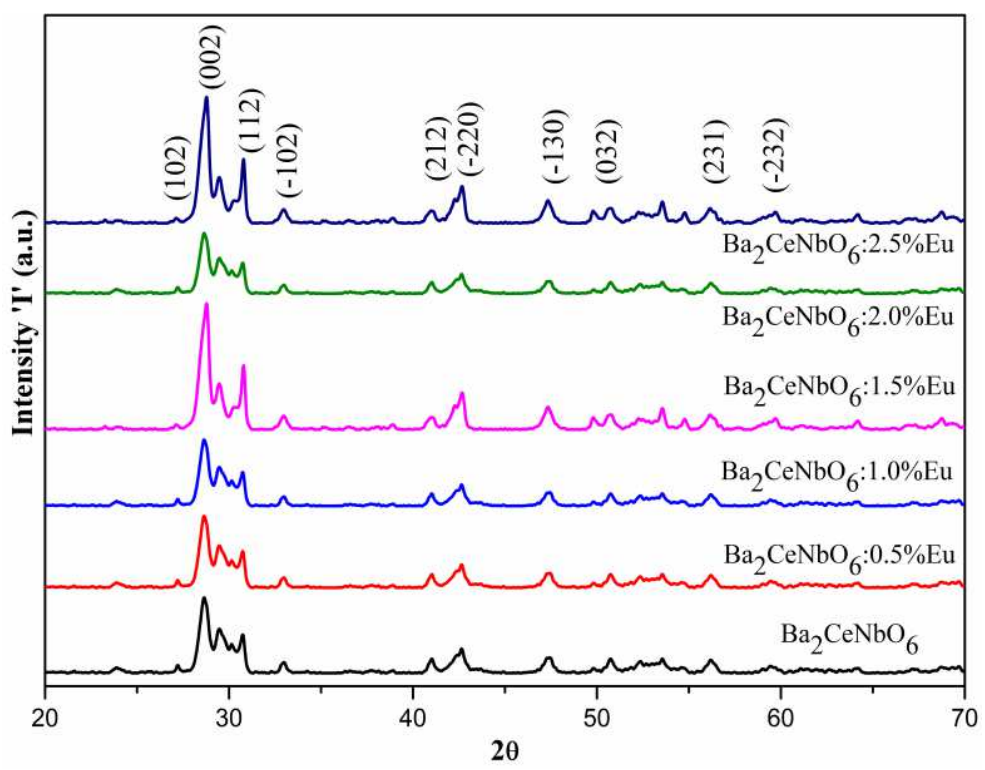

Figure 1 X-ray diffraction pattern of undoped and $\mathrm{Eu}(\mathrm{III})$ doped $\mathrm{Ba}_{2} \mathrm{CeNbO}_{6}$.

In double perovskite oxide, the study of distortion from the ideal cubic perovskite structure is clear as the $\mathrm{Ba}_{2} \mathrm{CeNbO}_{6}$ complex perovskite has general formula $\mathrm{A}_{2} \mathrm{BB}^{\prime} \mathrm{O}_{6}$. The tolerance factor $\mathrm{T}_{f}[29]$ of the $\mathrm{Ba}_{2} \mathrm{CeNbO}_{6}$ is calculated by using equation (2),

$$
T_{f}=\frac{R_{B a}+R_{O}}{\sqrt{2}\left(\frac{R_{C e}+R_{N b}}{2}+R_{O}\right)}
$$

Where, $\mathrm{R}_{\mathrm{Ba}}, \mathrm{R}_{\mathrm{Ce}}, \mathrm{R}_{\mathrm{Nb}}$ and $\mathrm{R}_{\mathrm{O}}$ are the ionic radii of $\mathrm{Ba}, \mathrm{Ce}, \mathrm{Nb}$ and $\mathrm{O}$ respectively [30]. By the geometry of crystal, the ideal cubic structure should have $\mathrm{T}_{f}=1$, whereas it will be monoclinic structure for values of $\mathrm{T}_{f}<1$ and it following the SPuDs prediction [31]. The value of tolerance factor for $\mathrm{Ba}_{2} \mathrm{CeNbO}_{6}$ was found to be approximately 0.9505 , which suggests that sample under study has the monoclinic structure. 


\begin{tabular}{ccccc}
\hline Atom & Site & $\boldsymbol{x}$ & $\boldsymbol{y}$ & $\boldsymbol{z}$ \\
\hline \hline $\mathrm{Ba}$ & $4 \mathrm{e}$ & 0.5000 & 0.5000 & 0.2395 \\
$\mathrm{Ce}$ & $2 \mathrm{c}$ & 0.0000 & 0.5000 & 0.0000 \\
$\mathrm{Nb}$ & $2 \mathrm{~d}$ & 0.5000 & 0.0000 & 0.0000 \\
$\mathrm{O}$ & $4 \mathrm{e}$ & 0.2692 & 0.2167 & 0.0000 \\
$\mathrm{O}$ & $4 \mathrm{e}$ & 0.2692 & 0.7833 & 0.0000 \\
$\mathrm{O}$ & $4 \mathrm{e}$ & 0.5000 & 0.0000 & 0.2255 \\
\hline
\end{tabular}

Table 1 Structural parameters of $\mathrm{Ba}_{2} \mathrm{CeNbO}_{6}$ found by Rietveld analysis of XRD data.

\begin{tabular}{|c|c|c|c|}
\hline Cation & Anion \& Multi. & Distance $(\AA)$ & Occupancy \\
\hline $\mathrm{Ce}(2 \mathrm{c})$ & $\mathrm{O}(4 \mathrm{e}) \times 2$ & 2.4475 & 1.00 \\
\hline $\mathrm{Ce}(2 \mathrm{c})$ & $\mathrm{O}(4 \mathrm{e}) \times 2$ & 2.4475 & 1.00 \\
\hline $\mathrm{Ce}(2 \mathrm{c})$ & $\mathrm{O}(4 \mathrm{e}) \times 2$ & 2.4075 & 1.00 \\
\hline $\mathrm{Nb}(2 \mathrm{~d})$ & $\mathrm{O}(4 \mathrm{e}) \times 2$ & 1.9824 & 1.00 \\
\hline $\mathrm{Nb}(2 \mathrm{~d})$ & $\mathrm{O}(4 \mathrm{e}) \times 2$ & 1.9824 & 1.00 \\
\hline $\mathrm{Nb}(2 \mathrm{~d})$ & $\mathrm{O}(4 \mathrm{e}) \times 2$ & 1.9785 & 1.00 \\
\hline $\mathrm{Ba}(4 \mathrm{e})$ & $\mathrm{O}(4 \mathrm{e}) \times 1$ & 3.1067 & 1.00 \\
\hline $\mathrm{Ba}(4 \mathrm{e})$ & $\mathrm{O}(4 \mathrm{e}) \mathrm{X} 1$ & 3.1471 & 1.00 \\
\hline $\mathrm{Ba}(4 \mathrm{e})$ & $\mathrm{O}(4 \mathrm{e}) \times 1$ & 3.1067 & 1.00 \\
\hline $\mathrm{Ba}(4 \mathrm{e})$ & $\mathrm{O}(4 \mathrm{e}) \mathrm{X} 1$ & 3.1471 & 1.00 \\
\hline $\mathrm{Ba}(4 \mathrm{e})$ & $\mathrm{O}(4 \mathrm{e}) \times 1$ & 3.1067 & 1.00 \\
\hline $\mathrm{Ba}(4 \mathrm{e})$ & $\mathrm{O}(4 \mathrm{e}) \mathrm{X} 1$ & 3.1471 & 1.00 \\
\hline $\mathrm{Ba}(4 \mathrm{e})$ & $\mathrm{O}(4 \mathrm{e}) \times 1$ & 3.1067 & 1.00 \\
\hline $\mathrm{Ba}(4 \mathrm{e})$ & $\mathrm{O}(4 \mathrm{e}) \mathrm{X} 1$ & 3.1471 & 1.00 \\
\hline $\mathrm{Ba}(4 \mathrm{e})$ & $\mathrm{O}(4 \mathrm{e}) \times 1$ & 3.1461 & 1.00 \\
\hline $\mathrm{Ba}(4 \mathrm{e})$ & $\mathrm{O}(4 \mathrm{e}) \mathrm{X} 1$ & 3.1461 & 1.00 \\
\hline $\mathrm{Ba}(4 \mathrm{e})$ & $\mathrm{O}(4 \mathrm{e}) \mathrm{X} 1$ & 3.1636 & 1.00 \\
\hline $\mathrm{Ba}(4 \mathrm{e})$ & $\mathrm{O}(4 \mathrm{e}) \mathrm{X} 1$ & 3.1636 & 1.00 \\
\hline
\end{tabular}

Table 2 Inter-atomic distance and occupancy calculated through Rietveld refinement of experimental data.

\section{Williomson - Hall Plot}

Figure 2 (a-f) shows $\mathrm{W}-\mathrm{H}$ plot of undoped and $\mathrm{Eu}$ (III) doped $\mathrm{Ba}_{2} \mathrm{CeNbO}_{6}$. The broadening effect of XRD peaks reflects the nanocrystalline nature of the resulting $\mathrm{Eu}(\mathrm{III})$ doped $\mathrm{Ba}_{2} \mathrm{CeNbO}_{6}$ samples. Since the effective XRD peak broadening can caused by lattice strain and small crystallite size, these two effects have to be distinguished. This can be 
calculated by plotting $\beta \cos \theta$ versus $\sin \theta$ in the following relation (equation 3) (WilliamsonHall plot) [28],

$$
\beta_{h k l} * \cos \theta_{h k l}=\left(\frac{k \lambda}{D}\right)+\varepsilon * \sin \theta_{h k l}
$$

The crystallite size and strain of $\mathrm{Eu}(\mathrm{III})$ doped $\mathrm{Ba}_{2} \mathrm{CeNbO}_{6}$ estimated from the intercept and slope are listed in table-3.
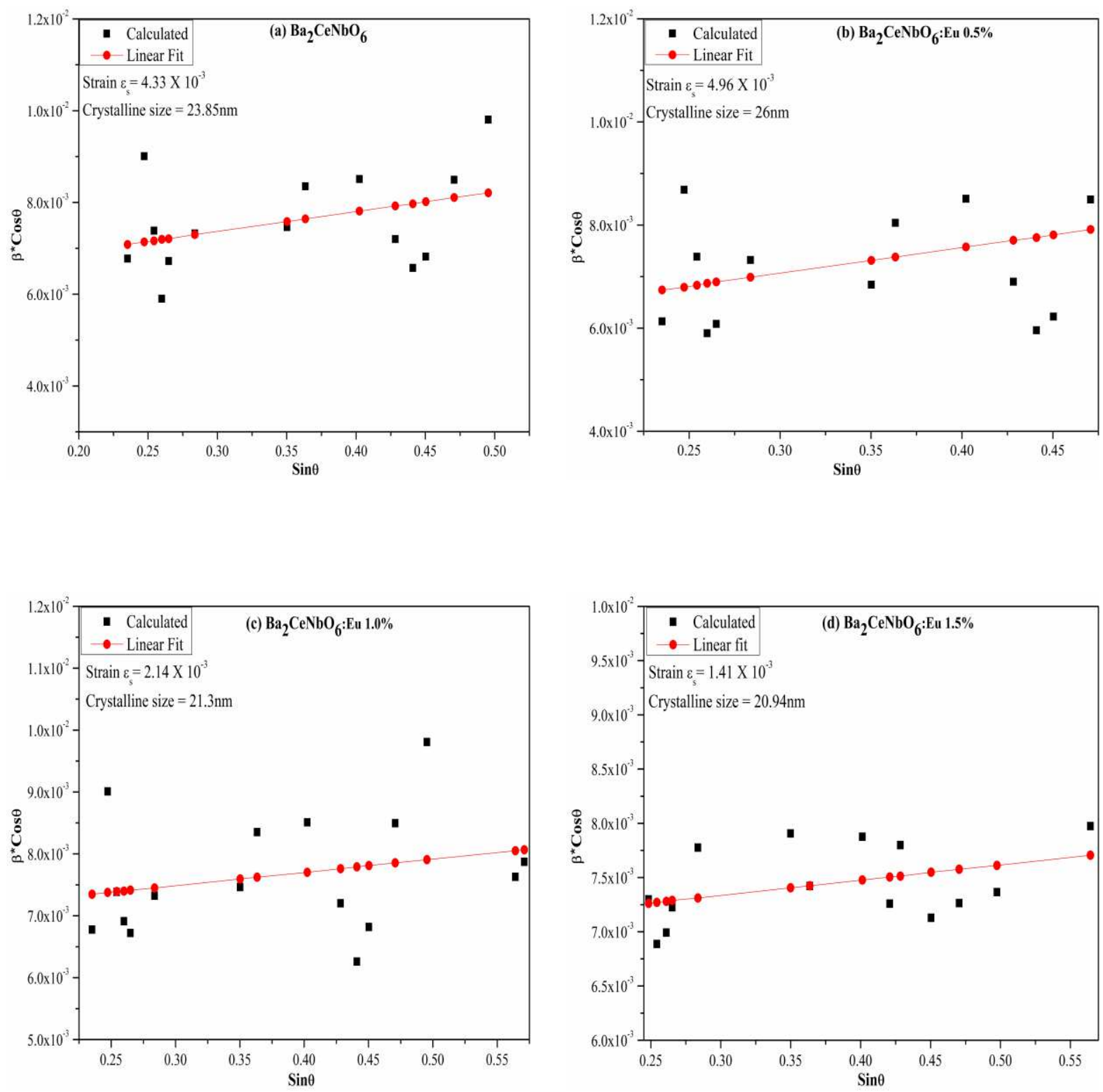

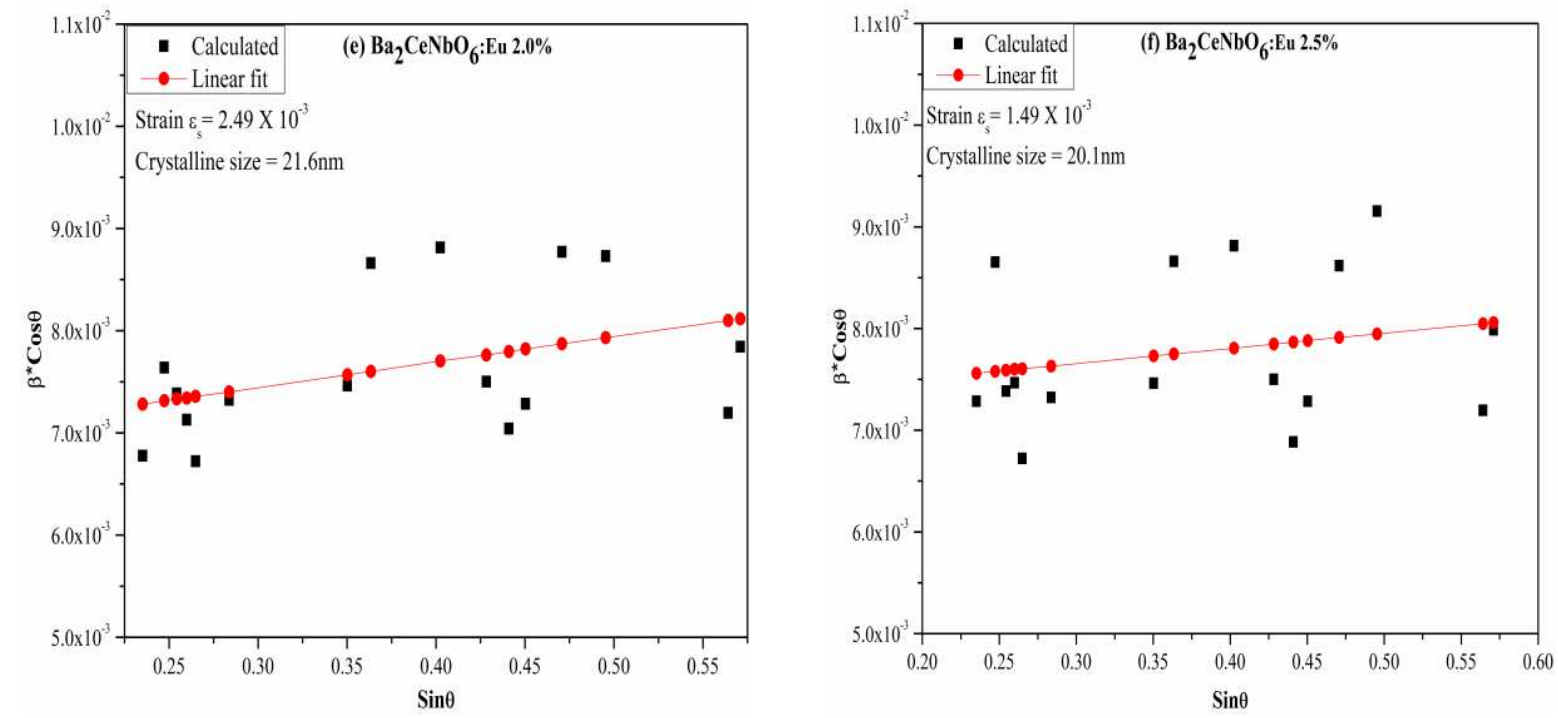

Figure-2 (a-f) Williomson-Hall plot of undoped and $\mathrm{Eu}(\mathrm{III})$ doped $\mathrm{Ba}_{2} \mathrm{CeNbO}_{6}$ 


\begin{tabular}{|c|c|c|c|c|c|c|c|}
\hline \multicolumn{2}{|c|}{ Sample } & $\mathrm{Ba}_{2} \mathrm{CeNbO}_{6}$ & $\begin{array}{c}\mathrm{Ba}_{2} \mathrm{CeNbO}_{6}: \mathrm{Eu}^{3+} \\
(0.5 \%)\end{array}$ & $\begin{array}{l}\mathrm{Ba}_{2} \mathrm{CeNbO}_{6}: \\
\mathrm{Eu}^{3+}(1.0 \%)\end{array}$ & $\begin{array}{c}\mathrm{Ba}_{2} \mathrm{CeNbO}_{6}: \mathrm{Eu}^{3+} \\
(1.5 \%)\end{array}$ & $\begin{array}{l}\mathrm{Ba}_{2} \mathrm{CeNbO}_{6}: \\
\mathrm{Eu}^{3+}(2.0 \%)\end{array}$ & $\begin{array}{l}\mathrm{Ba}_{2} \mathrm{CeNbO}_{6}: \\
\mathrm{Eu}^{3+}(2.5 \%)\end{array}$ \\
\hline \multicolumn{2}{|c|}{ Structure } & Monoclinic & Monoclinic & Monoclinic & Monoclinic & Monoclinic & Monoclinic \\
\hline \multicolumn{2}{|c|}{ Space Group } & $\mathrm{P} 2{ }_{1} / \mathrm{n}$ & $\mathrm{P} 2_{1} / \mathrm{n}$ & $\mathrm{P} 2{ }_{1} / \mathrm{n}$ & $\mathrm{P} 2_{1} / \mathrm{n}$ & $\mathrm{P} 2_{1} / \mathrm{n}$ & $\mathrm{P} 2{ }_{1} / \mathrm{n}$ \\
\hline Cell & $\mathbf{a}(\AA ̊ \AA)$ & $5.9012(2)$ & $5.9115(5)$ & $5.9052(7)$ & $5.9168(4)$ & $5.9132(3)$ & $5.9048(5)$ \\
\hline \multirow[t]{3}{*}{ Parameters } & $\mathbf{b}(\AA)$ & $6.1043(8)$ & $6.0854(3)$ & 6.0986(9) & $6.0943(5)$ & $6.1013(7)$ & $6.0972(8)$ \\
\hline & $\mathbf{c}(\stackrel{\AA}{)})$ & $8.0586(3)$ & $8.0795(2)$ & $8.0626(3)$ & $8.0746(6)$ & $8.0816(8)$ & $8.0716(4)$ \\
\hline & $\boldsymbol{\beta}$ & 90.06 & 90.05 & 89.96 & 89.93 & 90.12 & 89.98 \\
\hline \multicolumn{2}{|c|}{ Volume $(\AA)^{3}$} & 290.29 & 290.65 & 290.36 & 291.16 & 291.56 & 290.59 \\
\hline Average & Scherrer & 24.1 & 25.4 & 20.8 & 21.1 & 22.1 & 19.8 \\
\hline Crystallite & Method & & & & & & \\
\hline Size (nm) & $\begin{array}{l}\text { W-H } \\
\text { Plot }\end{array}$ & 23.8 & 25.9 & 21.3 & 20.9 & 21.6 & 20.1 \\
\hline \multicolumn{2}{|c|}{ Strain $(\varepsilon)$} & $4.33 \times 10^{-3}$ & $4.96 \times 10^{-3}$ & $2.14 \times 10^{-3}$ & $1.41 \times 10^{-3}$ & $2.49 \times 10^{-3}$ & $1.49 \times 10^{-3}$ \\
\hline
\end{tabular}

Table 3 Summery of cell parameter, volume and crystallite size of $\mathrm{Eu}(\mathrm{III})$ doped $\mathrm{Ba}_{2} \mathrm{CeNbO}_{6}$. 


\subsection{FTIR (Fourier Transform Infrared Spectrometry)}

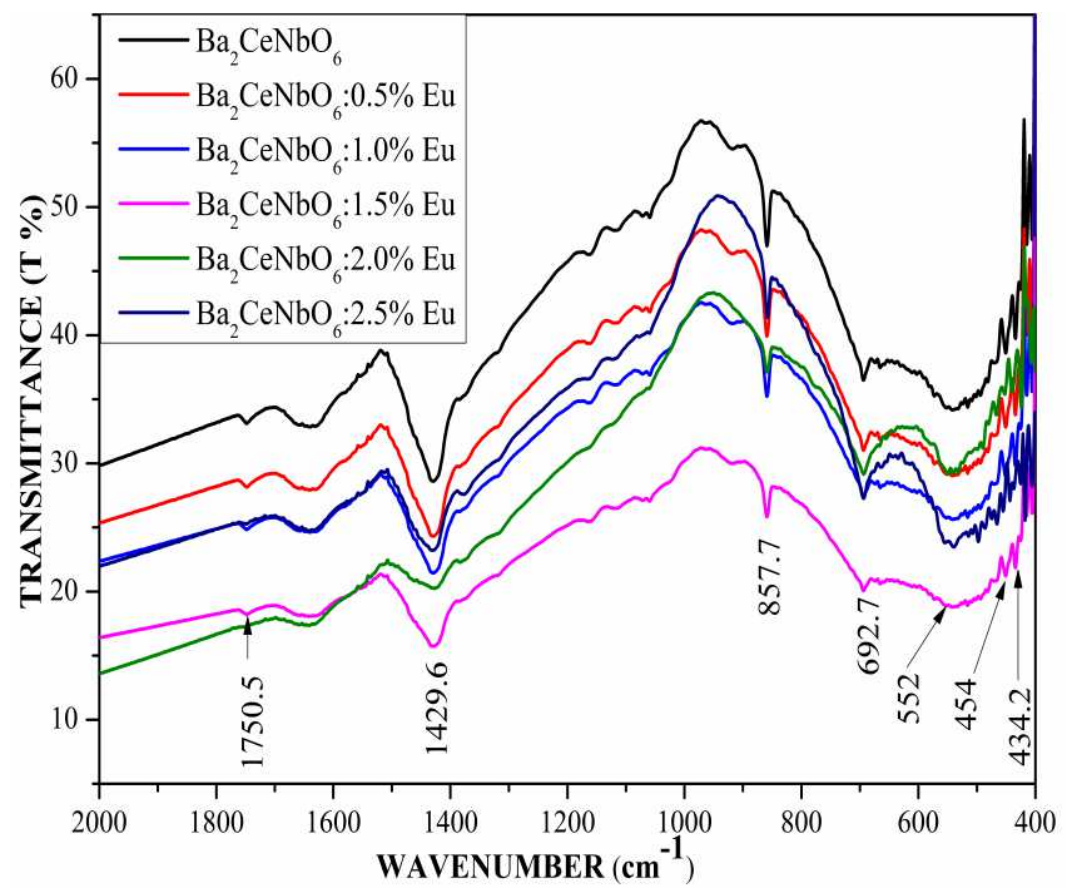

Figure 3 FTIR spectra of undoped and $\mathrm{Eu}(\mathrm{III})$ doped $\mathrm{Ba}_{2} \mathrm{CeNbO}_{6}$.

To discover the atomic bonds in a compound FTIR analysis has been carried out. In Fig.3 FTIR spectra of $\mathrm{Ba}_{2} \mathrm{CeNbO}_{6}$ has shown with a range of $400 \mathrm{~cm}^{-1}$ to $2000 \mathrm{~cm}^{-1}$ wavenumber. The FTIR spectrum of $\mathrm{Ba}_{2} \mathrm{CeNbO}_{6}$ shows some well-defined bands in the above figure. It is in good accordance with group theory predictions what orderly found for pervoskite type structures [32]. In pervoskite-type material, significant vibrational couplings may expect between the different coordination polyhedral compounds. All the peaks in the spectra are typical of the material. One small hump is at $1750 \mathrm{~cm}^{-1}$, which is due to the presence of adsorbed moisture in $\mathrm{KBr}$ [33]. The lower energy band found at around 450-650 $\mathrm{cm}^{-1}$ is related to the deformational mode of $\mathrm{CeO}_{6}$ octahedra [34]. The medium energy peak appearing near $850 \mathrm{~cm}^{-1}$ is due to the asymmetric $\mathrm{NbO}_{6}$ stretching vibration [35] due to the higher charge of the cation. The strong intensity peak at approximately $1430 \mathrm{~cm}^{-1}$ can eventually be related to the symmetric stretching vibration of $\mathrm{NbO}_{6}$ octahedra [36]. A small intensity peak at $1100 \mathrm{~cm}^{-1}$ likely corresponds to the presence of overtones of the fundamental vibrations in $\mathrm{Ba}_{2} \mathrm{CeNbO}_{6}$ [37]. The peak at $552 \mathrm{~cm}^{-1}$ is due to the $\mathrm{Ba}-\mathrm{O}$. 


\subsection{Photoluminescence studies}

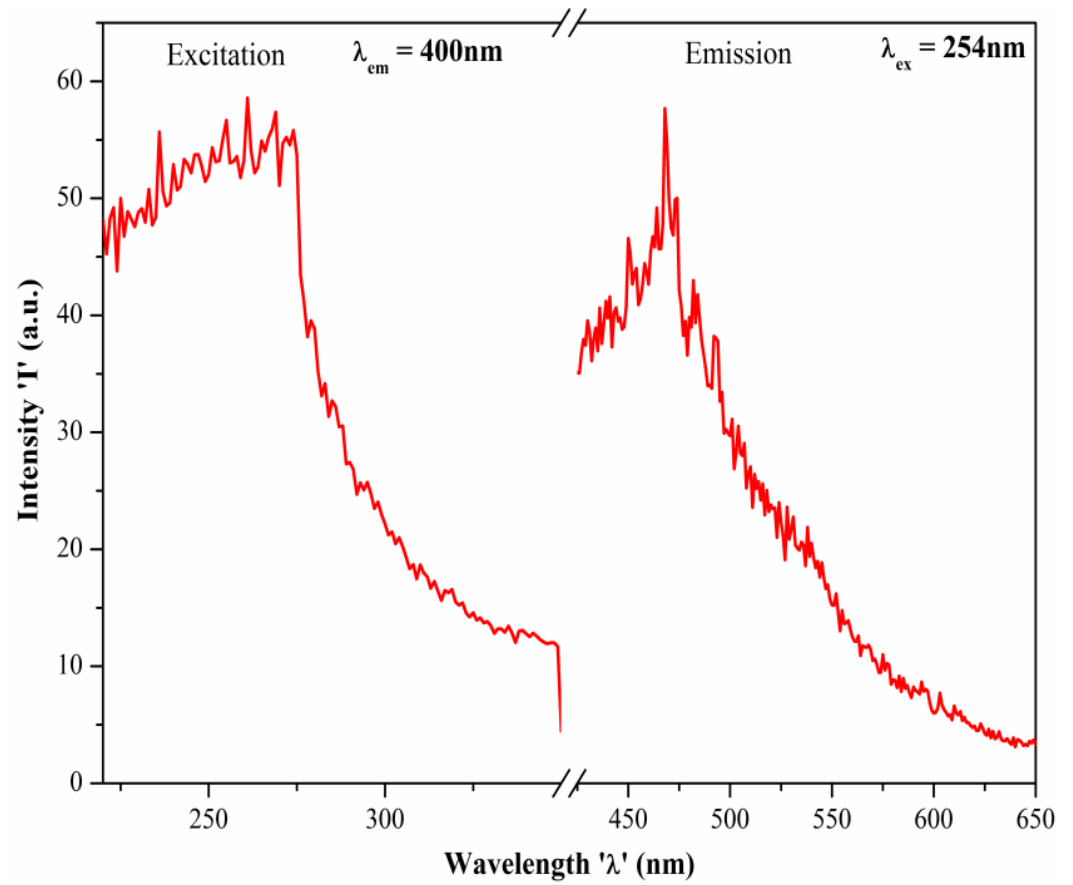

Figure 4 Photoluminescence spectra of $\mathrm{Ba}_{2} \mathrm{CeNbO}_{6}$.

Figure 4 shows room temperature excitation and emission spectra of undoped $\mathrm{Ba}_{2} \mathrm{CeNbO}_{6}$. Emission spectra of undoped $\mathrm{Ba}_{2} \mathrm{CeNbO}_{6}$ phosphor were recorded by exciting this phosphor with $254 \mathrm{~nm}$ wavelength and excitation spectra recorded with $400 \mathrm{~nm}$ emission wavelength.

Figure 5 represents the absorption spectra of $\mathrm{Eu}(\mathrm{III})$ doped $\mathrm{Ba}_{2} \mathrm{CeNbO}_{6}$ phosphor. These excitation spectra recorded with the $613 \mathrm{~nm}$ emission wavelength. An intense peak at $466 \mathrm{~nm}$ wavelength is due to the ${ }^{5} \mathrm{D}_{2} \leftarrow{ }^{7} \mathrm{~F}_{0}$ electric dipole transition [38]. The absorption spectra are less used and their analysis is also less useful. The main reason for this is that the most relevant transitions for the determination of the point group symmetry $\left({ }^{5} \mathrm{D}_{0} \leftarrow{ }^{7} \mathrm{~F}_{0}\right.$, ${ }^{5} \mathrm{D}_{1} \leftarrow{ }^{7} \mathrm{~F}_{1},{ }^{5} \mathrm{D}_{1} \leftarrow{ }^{7} \mathrm{~F}_{0},{ }^{5} \mathrm{D}_{2} \leftarrow{ }^{7} \mathrm{~F}_{1}$, and $\left.{ }^{5} \mathrm{D}_{2} \leftarrow{ }^{7} \mathrm{~F}_{0}\right)$ are very weak. The absorption spectra of Eu(III) compounds allows the determination of higher energy levels of the ${ }^{4} f_{6}$ electronic configuration of $\mathrm{Eu}^{3+}$ ion. In the earlier literature survey, the transitions to the ${ }^{5} \mathrm{D}_{0},{ }^{5} \mathrm{D}_{1}$, and ${ }^{5} \mathrm{D}_{2}$ levels were called the yellow, green and blue bands based on their places in the visible spectrum $[39,40]$. The transitions of ${ }^{5} \mathrm{D}_{0} \leftarrow{ }^{7} \mathrm{~F}_{1}$ and ${ }^{5} \mathrm{D}_{0} \leftarrow{ }^{7} \mathrm{~F}_{2}$ are suitable for determining the location of the ${ }^{5} \mathrm{D}_{0}$ level if the ${ }^{5} \mathrm{D}_{0} \leftarrow{ }^{7} \mathrm{~F}_{0}$ transition is forbidden. 


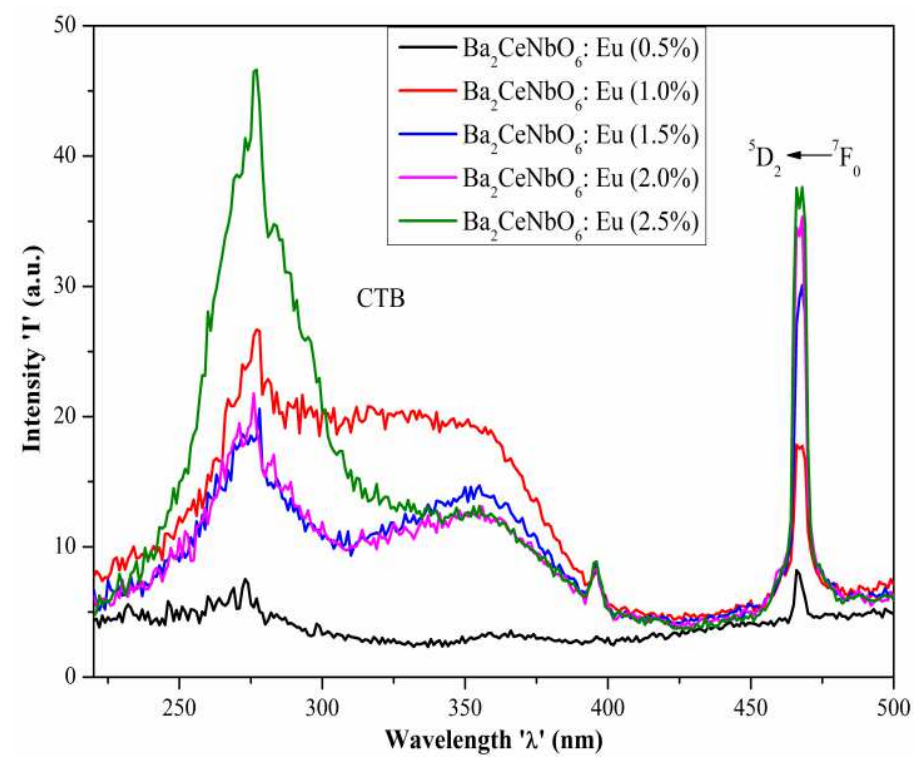

Figure 5 Photoluminescence Excitation spectra of $\mathrm{Eu}(\mathrm{III})$ doped $\mathrm{Ba}_{2} \mathrm{CeNbO}_{6}$

For transitions to the ${ }^{5} \mathrm{D}_{2}$ level, the ${ }^{5} \mathrm{D}_{2} \leftarrow{ }^{7} \mathrm{~F}_{0}$ transition is the most useful, because it allows determining the location of the ${ }^{5} \mathrm{D}_{2}$ level. This ${ }^{5} \mathrm{D}_{2} \leftarrow{ }^{7} \mathrm{~F}_{0}$ electric dipole transition is hypersensitive $(\Delta \mathrm{J}=2)$. The hypersensitivity of the ${ }^{5} \mathrm{D}_{2} \leftarrow{ }^{7} \mathrm{~F}_{0}$ transition is very well explained by examining the europium(III) dipicolinate system [41]. The ${ }^{5} \mathrm{D}_{2}$ level is often used to directly excite the $\mathrm{Eu}^{3+}$ ion with one of the lines of an argon-ion laser $(465.8 \mathrm{~nm})$ or with a diode laser.

Europium (III) also shows broad absorption bands in the UV region of the electromagnetic spectrum. This broad absorption band is due to an electron transfer from one or more adjacent atoms to the $\mathrm{Eu}^{3+}$ ion. $\mathrm{Eu}^{3+}$ is the most oxidizing ion of the trivalent rareearth ions as it requires only a single electron to achieve a half-filled stable shell. These absorption bands in the UV region are so-called charge-transfer bands (CTB) or ligand-tometal charge transfer (LMCT) bands. These absorption bands are very intense related to the $\mathrm{f}-\mathrm{f}$ transitions as these transitions are allowed by the Laporte selection rule [42]. The location of charge-transfer bands strongly depending on the nature of the ligands. The relationship between the nature of the ligands and the position of the charge-transfer bands was first recognized by Ryan and Jørgensen [43] but, it was studied by Dorenbos [44, 45] in more detail. Dorenbos gives an extensive compilation of the energies of the charge-transfer transitions of $\mathrm{Eu}(\mathrm{III})$ compounds in the solid state [45]. The general trend of the energies of the charge-transfer transitions is: fluorides $>$ oxides $>$ nitrides $>$ chlorides $>$ bromides $>$ iodides $>$ sulfides $>$ selenides $>$ phosphides $>$ arsenides $>$ tellurides $>$ antimonides [38]. 
Charge-transfer states of $\mathrm{Eu}^{3+}$ at low energies possess severe consequences for the spectroscopic characteristics of $\mathrm{Eu}^{3+}$ ion, due to the non-negligible mixing of the ${ }^{4} \mathrm{f}_{6}$ electronic states and the charge-transfer states. This mixing has been utilized to explain the high intensity of the ${ }^{5} \mathrm{D}_{0} \rightarrow{ }^{7} \mathrm{~F}_{0}$ transition in some europium(III) compounds [46]. Chargetransfer bands also useful for the sensitization of europium(III) luminescence as they can work as aerial to consume energy and transfer this excitation energy to the $\mathrm{Eu}^{3+}$ ion.
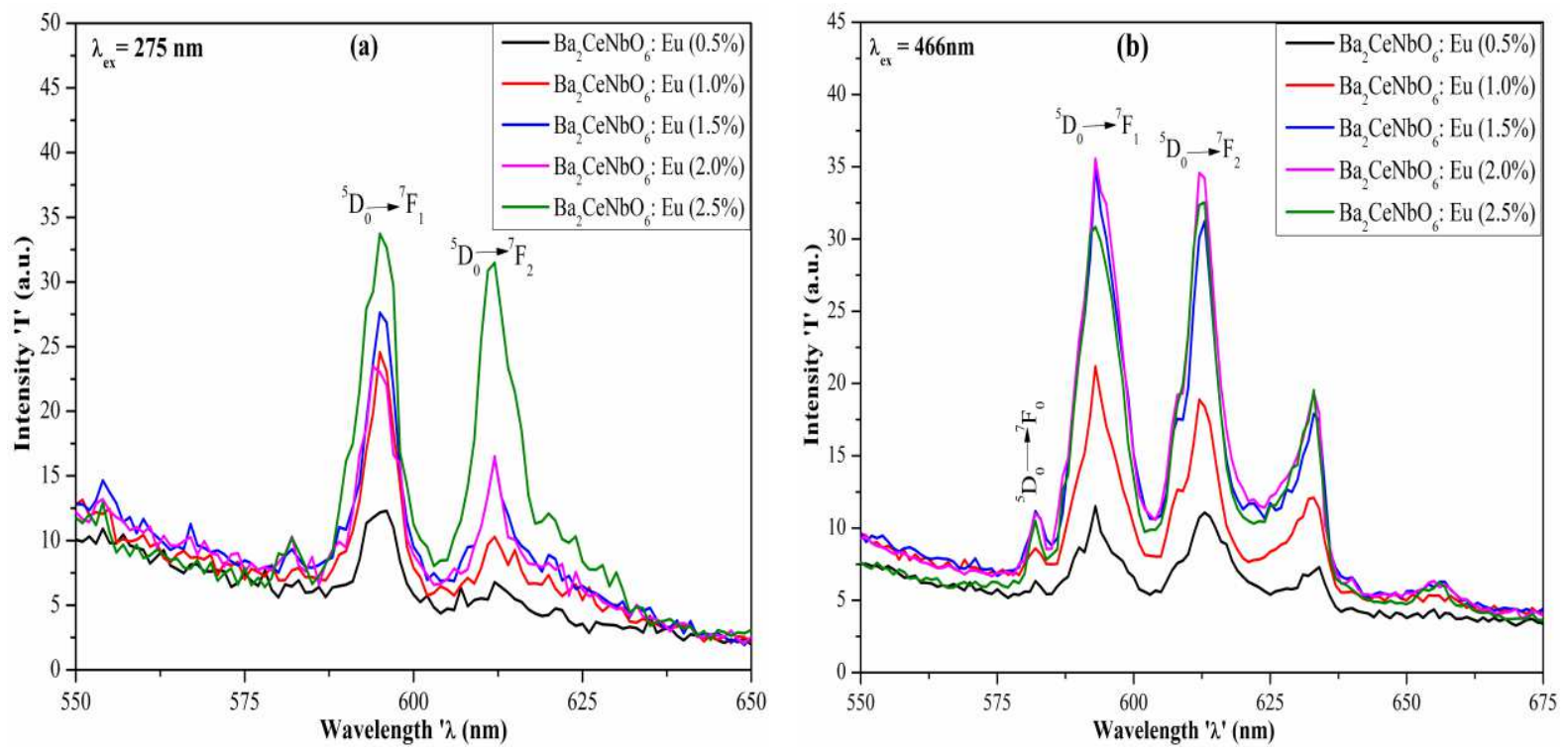

Figure 6 Photoluminescence emission spectra of $\mathrm{Eu}(\mathrm{III})$ doped $\mathrm{Ba}_{2} \mathrm{CeNbO}_{6}$ with excitation wavelengths (a) $275 \mathrm{~nm}$ and (b) $466 \mathrm{~nm}$.

Fig. 6 (a) and (b) depict typical PL emission spectra of $\mathrm{Eu}$ (III) doped $\mathrm{Ba}_{2} \mathrm{CeNbO}_{6}$ phosphors excited with $275 \mathrm{~nm}$ and $466 \mathrm{~nm}$ wavelength. In the present study, the concentration of europium ranges from 0.5 to 2.5 mole percentage. The Eu (III) doped $\mathrm{Ba}_{2} \mathrm{CeNbO}_{6}$ phosphors exhibit two visible emission bands around 596 and $613 \mathrm{~nm}$ when excited at $275 \mathrm{~nm}$ while it displays four emission peaks at 582nm, 596nm, 613nm, and $633 \mathrm{~nm}$. These emission peaks are assigned to the magnetic dipole (MD) ${ }^{5} \mathrm{D}_{0} \rightarrow{ }^{7} \mathrm{~F}_{1}$ and electric dipole (ED) ${ }^{5} \mathrm{D}_{0} \rightarrow{ }^{7} \mathrm{~F}_{2}$ transitions of europium when excited with $275 \mathrm{~nm}$ and $466 \mathrm{~nm}$. The emission peak at $596 \mathrm{~nm}$ is due to the magnetic dipole transition of ${ }^{5} \mathrm{D}_{0} \rightarrow{ }^{7} \mathrm{~F}_{1}$, which has higher intensity compare to peak at $613 \mathrm{~nm}$ of ${ }^{5} \mathrm{D}_{0} \rightarrow{ }^{7} \mathrm{~F}_{2}$ electric dipole transition during excitation at $275 \mathrm{~nm}$. This asymmetricity confirms that the $\mathrm{Eu}^{3+}$ ions are located at the noninversion symmetric sites in host material [47 - 49]. When this phosphor was excited at $466 \mathrm{~nm}$ emission peaks are observed at around $580-600 \mathrm{~nm}$, this is mainly due to the magnetic 
dipole transition of ${ }^{5} \mathrm{D}_{0} \rightarrow{ }^{7} \mathrm{~F}_{0}$ and ${ }^{5} \mathrm{D}_{0} \rightarrow{ }^{7} \mathrm{~F}_{1}$ and emission peak at $613 \mathrm{~nm}$ and $633 \mathrm{~nm}$ are due to electric dipole transition of the ${ }^{5} \mathrm{D}_{0} \rightarrow{ }^{7} \mathrm{~F}_{2}$.

It's important to note that in both the emission spectra emission peak at around $613 \mathrm{~nm}$ is occurred in the red region. Though an admixture of odd-parity electronic configuration to the pure $4 \mathrm{f}$ (like a non-centrosymmetric crystal field component) $[50,51]$ will allow the ED transitions partially and their possibility of occurrence is much higher than the probability of parity-allowed magnetic dipole (MD) $\left({ }^{5} \mathrm{D}_{0} \rightarrow{ }^{7} \mathrm{~F}_{1}\right)$ transition. The site symmetry of Eu ${ }^{3+}$ ion in the host lattice can be predicted by asymmetry ratio, which can be defined as equation (4),

$$
\text { Asymmetry }- \text { ratio }=\frac{I\left({ }^{5} D_{0} \rightarrow^{7} F_{2}\right)}{I\left({ }^{5} D_{0} \rightarrow^{7} F_{1}\right)}
$$

Where, I $\left({ }^{5} \mathrm{D}_{0} \rightarrow{ }^{7} \mathrm{~F}_{2}\right)$ and $\mathrm{I}\left({ }^{5} \mathrm{D}_{0} \rightarrow{ }^{7} \mathrm{~F}_{1}\right)$ are the intensities of electric dipole and magnetic dipole transitions respectively. When asymmetry ratio $>1$, then Eu (III) substituted at the noncentrosymmetric site, and the asymmetry ratio $<1$ then $\mathrm{Eu}(\mathrm{III})$ substituted at a centrosymmetric site in the host lattice. Table 4 shows the asymmetry ratio for both emission spectra. In the present research, the asymmetric ratio is found to be less than unity (1), indicates that $\mathrm{Eu}$ (III) is substituted at a non-centrosymmetric site in the host lattice, and it's in good agreement with the earlier report [49, $52-56]$. It saw that the substitution of Eu (III) at the place of $\mathrm{Ba}$ (II) site in $\mathrm{Ba}_{2} \mathrm{CeNbO}_{6}$ is followed by $\mathrm{Ba}$ (II) ion vacancy due to a distinct ionic radius. These gaps in lattice reduce the local site symmetry at the $\mathrm{Eu}(\mathrm{III})$ site and act as a luminescence quenching center.

\begin{tabular}{ccc}
\hline \multirow{2}{*}{ Sample } & \multicolumn{2}{c}{ Asymmetry Ratio } \\
\cline { 2 - 3 } & at 275nm & at 466nm \\
\hline \hline $\mathrm{Ba}_{2} \mathrm{CeNbO}_{6}: \mathrm{Eu}(0.5 \%)$ & 0.550 & 0.974 \\
$\mathrm{Ba}_{2} \mathrm{CeNbO}_{6}: \mathrm{Eu}(1 \%)$ & 0.419 & 0.896 \\
$\mathrm{Ba}_{2} \mathrm{CeNbO}_{6}: \mathrm{Eu}(1.5 \%)$ & 0.597 & 0.908 \\
$\mathrm{Ba}_{2} \mathrm{CeNbO}_{6}: \mathrm{Eu}(2 \%)$ & 0.704 & 0.978 \\
$\mathrm{Ba}_{2} \mathrm{CeNbO}_{6}: \mathrm{Eu}(2.5 \%)$ & 0.933 & 1.055 \\
\hline
\end{tabular}

Table 4 Asymmetric ratio of $\mathrm{Eu}(\mathrm{III})$ doped $\mathrm{Ba}_{2} \mathrm{CeNbO}_{6}$ at $275 \mathrm{~nm}$ and $466 \mathrm{~nm}$ emission spectra.

The results presented in Fig. 6 ( $\mathrm{a} \& \mathrm{~b}$ ) reveal that the spectral profile of the phosphors show noticeable changes with increasing europium concentration and the mixed overall emission light chromaticity. 


\section{CIE (Commission International del'éclairage)}

The chromaticity color coordinates of all phosphors were determined, and the results are presented in the Commission International del'éclairage (CIE) 1931 diagram, as shown in Fig. 7 (a) and (b). With increasing europium (III) concentration, the color tone of the emanating light shifts from the orange region to the red region [55, 57 - 59]. It's good to point out that the continuity of the emission tone corresponding to coordinate points shown in Fig. 7 by exciting the sample at $275 \mathrm{~nm}$ and $466 \mathrm{~nm}$ wavelength. This allows a mixture of light with color in the white-light region supports the intense glow correlated color temperature, i.e., CCT in the $1800-5000 \mathrm{~K}$ temperature range. We have indeed simulated the generation flow CCT white-light using xenon lamp of the phosphors reported here and the CIE1931 coordinates, and associated correlated color temperature (CCT) of the all phosphors presented in Table 5.
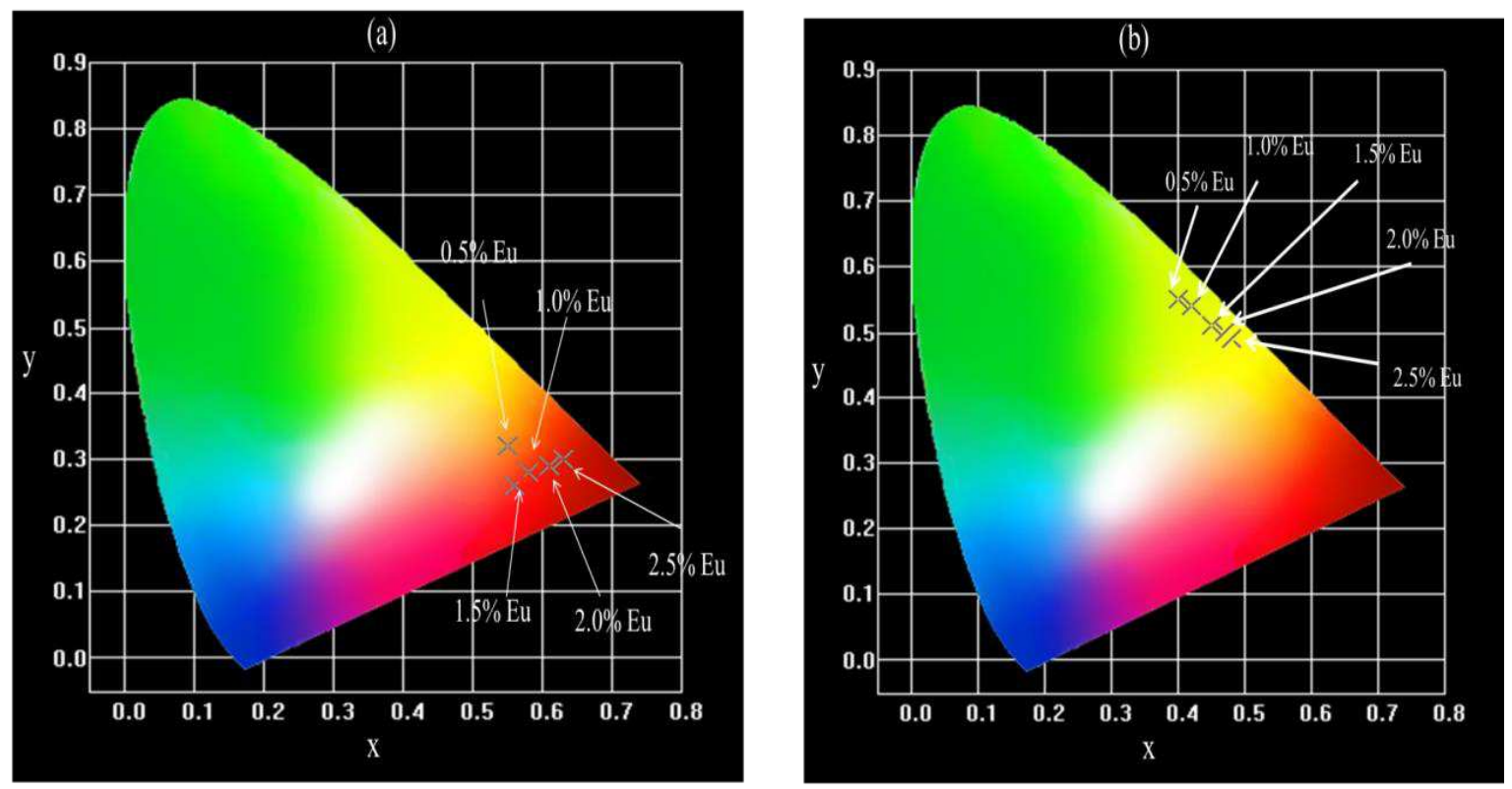

Figure $7 \mathrm{CIE}$ diagram of $\mathrm{Eu}(\mathrm{III})$ doped $\mathrm{Ba}_{2} \mathrm{CeNbO}_{6}$ emission at (a) $275 \mathrm{~nm}$ and (b) $466 \mathrm{~nm}$. 


\begin{tabular}{|c|c|c|c|c|c|c|c|c|c|}
\hline \multirow{3}{*}{$\begin{array}{l}\text { Sr. } \\
\text { No. }\end{array}$} & \multirow{3}{*}{ Sample } & \multicolumn{4}{|c|}{$275 \mathrm{~nm}$} & \multicolumn{4}{|c|}{$466 \mathrm{~nm}$} \\
\hline & & \multirow{2}{*}{$\mathbf{x}$} & \multirow{2}{*}{$\mathbf{y}$} & \multicolumn{2}{|c|}{ CCT } & \multirow{2}{*}{$\mathbf{x}$} & \multirow{2}{*}{ y } & \multicolumn{2}{|c|}{ CCT } \\
\hline & & & & Calcu. & Software & & & Calculated & Software \\
\hline 1 & $\mathrm{Ba}_{2} \mathrm{CeNbO}_{6}: \mathrm{Eu}(0.5 \%)$ & 0.55 & 0.32 & 1813.4 & 1825 & 0.40 & 0.55 & 4366.3 & 4359 \\
\hline 2 & $\mathrm{Ba}_{2} \mathrm{CeNbO}_{6}: \mathrm{Eu}(1 \%)$ & 0.58 & 0.28 & 3795.6 & 3798 & 0.42 & 0.54 & 4035.8 & 4028 \\
\hline 3 & $\mathrm{Ba}_{2} \mathrm{CeNbO}_{6}: \mathrm{Eu}(1.5 \%)$ & 0.56 & 0.26 & 4809.9 & 4813 & 0.45 & 0.51 & 3482.2 & 3476 \\
\hline 4 & $\mathrm{Ba}_{2} \mathrm{CeNbO}_{6}: \mathrm{Eu}(2 \%)$ & 0.61 & 0.29 & 3880.2 & 3878 & 0.47 & 0.50 & 3165.4 & 3161 \\
\hline 5 & $\mathrm{Ba}_{2} \mathrm{CeNbO}_{6}: \mathrm{Eu}(2.5 \%)$ & 0.63 & 0.30 & 3739.8 & 3742 & 0.48 & 0.49 & 2983.3 & 2981 \\
\hline
\end{tabular}

Table 5 CIE 1931 coordinates and CCT of the emissions under (275nm and 466nm) xenon lamp excitation. 


\section{Conclusion}

$\mathrm{Eu}^{3+}$ doped Barium Cerium Niobate $(\mathrm{BCN})$ oxide has been synthesizing by the combustion synthesis method. The X-ray diffraction measurement of Barium Cerium Niobate (BCN) oxide reveals that phosphor has a monoclinic phase with space group $\mathrm{P} 2{ }_{1} / \mathrm{n}$ (\# 014). Prepared pervoskite phosphor is nanocrystalline measured through Scherr's method and Williamson-hall plot method.

FTIR of $\mathrm{Ba}_{2} \mathrm{CeNbO}_{6}$ gives information that phosphor has a nano-size perovskite structure with an edge-connected $\mathrm{Nb}-\mathrm{O}$ octahedral. A small intensity peak at $1100 \mathrm{~cm}^{-1}$ likely corresponds to the overtone existence of the fundamental vibrations in $\mathrm{Ba}_{2} \mathrm{CeNbO}_{6}$.

A Photoluminescence study of $\mathrm{Eu}^{3+}$ doped $\mathrm{Ba}_{2} \mathrm{CeNbO}_{6}$ phosphor reveals that $\mathrm{Eu}$ (III) substituted at a non-centrosymmetric site in the host lattice. The substitution of $\mathrm{Eu}^{3+}$ at $\mathrm{Ba}^{2+}$ site in $\mathrm{Ba}_{2} \mathrm{CeNbO}_{6}$ is followed by $\mathrm{Ba}^{2+}$ ion vacancy due to charge imbalance and lattice strain due to different ionic radius. With increasing europium concentration, color tone of the emanating light shifts from orange to the red region. The emission color corresponding to coordinate points yields a mixture of light with color in the orange-red area with glow correlated color temperature, i.e., CCT in the $1800 \mathrm{~K}-5000 \mathrm{~K}$ range. These phosphors have prominent applications for solid-state lightning and red LED.

\section{Acknowledgments}

Author is very thankful to UGC-DAE Consortium for Scientific Research, Indore for XRD measurements.

\section{Authors Contribution}

Mr. Vishwnatha R. Verma contributed synthesis, XRD analysis, manuscript preparation and communication. Dr. Nimesh P. Patel contributed in analysis of FTIR and photoluminescence. Prof. M. Srinivas contributed in manuscript preparation. Dr. K.V.R. Murthy carried out PL experiment and interpretation of PL result.

\section{Funding}

Authors do not receive any funding from any institutions or agencies.

\section{Data Availability}

All data generated or analysed during this study are included in this published article. 


\section{Compliance with Ethical Standards}

\section{Conflict of Interests}

All the authors declare that they do not have any competing interest.

\section{Code Availability}

"Not Applicable".

\section{References}

[1] S. K. Korchagina, N. V. Golubko, Y. A. Shevchuk, and V. V. Gagulin, "Dilatometry and Dielectric Properties of Ba $2 \mathrm{RTaO} 6(\mathrm{R}=\mathrm{La}, \mathrm{Pr}, \mathrm{Sm}$, Dy) Ceramics," Inorg. Mater., vol. 40, no. 10, pp. 1088-1090, Oct. 2004.

[2] S. K. Korchagina and Y. A. Shevchuk, "Low-frequency and microwave dielectric properties of Ba2LnTaO6 ( $\mathrm{Ln}=\mathrm{La}, \mathrm{Pr}, \mathrm{Sm}, \mathrm{Dy}, \mathrm{Ce}, \mathrm{Gd}, \mathrm{Nd}, \mathrm{Tm}, \mathrm{Tb})$ ceramics," Inorg. Mater., vol. 42, no. 1, pp. 64-67, Jan. 2006.

[3] T. G. N. Babu and J. Koshy, "Ba2RETaO6(RE= Pr, Nd, Eu, and Dy), A Group of Chemically Stable Substrates for YBa2Cu3O7-8Films," J. Solid State Chem., vol. 126, no. 2, pp. 202-207, Nov. 1996.

[4] J. Kurian, J. Koshy, P. R. S. Wariar, Y. P. Yadava, and A. D. Damodaran, "Synthesis and Characterization of Rare-Earth Barium Antimonates, a New Group of Complex Perovskites Suitable as Substrates for YBa2Cu3O7- $\delta$ Films," J. Solid State Chem., vol. 116, no. 1, pp. 193-198, Apr. 1995.

[5] J. Kurian, A. M. John, P. K. Sajith, J. Koshy, S. P. Pai, and R. Pinto, "Growth of YBCO $-\mathrm{Ag}$ thin films $(\mathrm{Tc}(0)=90 \mathrm{~K})$ by pulsed laser ablation on polycrystalline Ba2EuNbO6; A new perovskite ceramic substrate for YBCO films," Mater. Lett., vol. 34, no. 3-6, pp. 208-212, Mar. 1998.

[6] E. J. Cussen, D. R. Lynham, and J. Rogers, "Magnetic Order Arising from Structural Distortion: Structure and Magnetic Properties of Ba 2 LnMoO 6," Chem. Mater., vol. 18, no. 12, pp. 2855-2866, Jun. 2006.

[7] W. T. A. Harrison, K. P. Reis, A. J. Jacobson, L. F. Schneemeyer, and J. V. Waszczak, "Syntheses, Structures, and Magnetism of Barium/Rare-Earth/Bismuth Double Perovskites. Crystal Structures of Ba2MBiO6 ( $\mathrm{M}=\mathrm{Ce}, \mathrm{Pr}, \mathrm{Nd}, \mathrm{Tb}, \mathrm{Yb})$ by Powder Neutron Diffraction,” Chem. Mater., vol. 7, no. 11, pp. 2161-2167, Nov. 1995.

[8] Y. Doi and Y. Hinatsu, "Magnetic properties of ordered perovskites Ba 2 LnTaO 6 (Ln 
= Y, lanthanides)," J. Phys. Condens. Matter, vol. 13, no. 19, pp. 4191-4202, May 2001.

[9] K. Henmi, Y. Hinatsu, and N. M. Masaki, "Crystal Structures and Magnetic Properties of Ordered Perovskites Ba2LnNbO6 (Ln=Lanthanide Elements), J. Solid State Chem., vol. 148, no. 2, pp. 353-360, Dec. 1999.

[10] Y. Hinatsu et al., "Studies on magnetic and calorimetric properties of double perovskites Ba2HoRuO6 and Ba2HoIrO6,” J. Solid State Chem., vol. 177, no. 1, pp. 38-44, Jan. 2004.

[11] C. C. Yu et al., "Enhanced photoluminescence of Ba2GdNbO6: Eu3+/Dy3+ phosphors by Li+ doping," J. Solid State Chem., vol. 180, no. 11, pp. 3058-3065, Nov. 2007.

[12] G. King and P. M. Woodward, "Cation ordering in perovskites," J. Mater. Chem., vol. 20, no. 28 , p. $5785,2010$.

[13] E. A. R. Assirey, "Perovskite synthesis, properties and their related biochemical and industrial application,” Saudi Pharm. J., vol. 27, no. 6, pp. 817-829, Sep. 2019.

[14] L. Chouhan, S. Ghimire, C. Subrahmanyam, T. Miyasaka, and V. Biju, "Synthesis, optoelectronic properties and applications of halide perovskites," Chem. Soc. Rev., 2020.

[15] L. Brixner, "Preparation and crystallographic study of some new rare earth compounds," J. Inorg. Nucl. Chem., vol. 15, no. 3-4, pp. 352-355, Oct. 1960.

[16] M. Takata and K. Kageyama, "Microwave Characteristics of A(B3+1/2B5+1/2)O3 Ceramics $(\mathrm{A}=\mathrm{Ba}, \mathrm{Ca}, \mathrm{Sr} ; \mathrm{B} 3+=\mathrm{La}, \mathrm{Nd}, \mathrm{Sm}, \mathrm{Yb} ; \mathrm{B} 5+=\mathrm{Nb}, \mathrm{Ta})$, , J. Am. Ceram. Soc., vol. 72, no. 10, pp. 1955-1959, Oct. 1989.

[17] F. V. S and F. E. G, "Preparation and Unit-Cell Parameters of Ä2ÇIBIIO6 Compounds," Kristallografiya, vol. 6, no. 5, pp. 770-772, 1961.

[18] M. ANDERSON, K. GREENWOOD, G. TAYLOR, and K. POEPPELMEIER, "Bcation arrangements in double perovskites," Prog. Solid State Chem., vol. 22, no. 3, pp. 197-233, 1993.

[19] U. Amador, C. J. D. Hetherington, E. Moran, and M. A. Alario-Franco, "Ba2PrPtO6: A novel double perovskite," J. Solid State Chem., vol. 96, no. 1, pp. 132-140, Jan. 1992.

[20] G. Blasse, "New compounds with perovskite-like structures," J. Inorg. Nucl. Chem., vol. 27, no. 5, pp. 993-1003, May 1965.

[21] M. P. Attfield, P. D. Battle, S. K. Bollen, T. C. Gibb, and R. J. Whitehead, "The crystal 
structure and magnetic properties of SrLaFeSnO6 and SrLaNiSbO6," J. Solid State Chem., vol. 100, no. 1, pp. 37-48, Sep. 1992.

[22] P. D. Battle, J. B. Goodenough, and R. Price, "The crystal structures and magnetic properties of Ba2LaRuO6 and Ca2LaRuO6," J. Solid State Chem., vol. 46, no. 2, pp. 234-244, Feb. 1983.

[23] R. ROY, "Multiple Ion Substitution in the Perovskite Lattice," J. Am. Ceram. Soc., vol. 37, no. 12, pp. 581-588, Dec. 1954.

[24] M. P. Attfield, P. D. Battle, S. K. Bollen, S. H. Kim, A. V. Powell, and M. Workman, "Structural and electrical studies of mixed copper/ruthenium oxides and related compounds of zinc and antimony,” J. Solid State Chem., vol. 96, no. 2, pp. 344-359, Feb. 1992.

[25] M. T. Anderson and K. R. Poeppelmeier, "Lanthanum copper tin oxide (La2CuSnO6): a new perovskite-related compound with an unusual arrangement of B cations," Chem. Mater., vol. 3, no. 3, pp. 476-482, May 1991.

[26] M. Srinivas, V. Verma, N. Patel, D. Modi, D. Tawde, and K. V. R. Murthy, "Characterization of newly synthesized Strontium Cerium Niobate nanophosphor," J. Lumin., vol. 147, pp. 324-327, Mar. 2014.

[27] A. Dutta and T. P. Sinha, "Dielectric Relaxation and Electronic Structure of Double Perovskite Ca2AlNbO6," Integr. Ferroelectr., vol. 116, no. July 2015, pp. 41-50, 2010.

[28] C. Suryanarayana and M. G. Norton, X-Ray Diffraction, 1st ed. Boston, MA: Springer US, 1998.

[29] V. M. Goldschmidt, "Die Gesetze der Krystallochemie," Naturwissenschaften, vol. 14, no. 21, pp. 477-485, 1926.

[30] R. D. Shannon, "Revised effective ionic radii and systematic studies of interatomic distances in halides and chalcogenides," Acta Crystallogr. Sect. A, vol. 32, no. 5, pp. 751-767, Sep. 1976.

[31] M. W. Lufaso and P. M. Woodward, "Prediction of the crystal structures of perovskites using the software program SPuDS," Acta Crystallogr. Sect. B, vol. 57, no. 6, pp. 725-738, 2001.

[32] M. Licheron, F. Gervais, J. Coutures, and J. Choisnet, “'Ba2BiO4' surprisingly found as a cubic double perovskite," Solid State Commun., vol. 75, no. 9, pp. 759-763, Sep. 1990. 
[33] J. E. Yoo and J. Choi, "Surfactant-assisted growth of anodic nanoporous niobium oxide with a grained surface," Electrochim. Acta, vol. 55, no. 18, pp. 5142-5147, Jul. 2010.

[34] Y. Huang, T. Wei, and Y. Ge, "Preparation and characterization of novel Ce(III)gelatin complex,” J. Appl. Polym. Sci., vol. 108, no. 6, pp. 3804-3807, Jun. 2008.

[35] J. LIN et al., "Crystallization of $\mathrm{TeO} 2-\mathrm{Nb} 2 \mathrm{O} 5$ glasses and their network structural evolution," Mater. Sci., vol. 27, p. 329, 2009.

[36] X. Jin, D. Sun, M. Zhang, Y. Zhu, and J. Qian, "Investigation on FTIR spectra of barium calcium titanate ceramics," J. Electroceramics, vol. 22, no. 1-3, pp. 285-290, Feb. 2009.

[37] A. E. Lavat, M. C. Grasselli, E. J. Baran, and R. C. Mercader, "Spectroscopic characterization of $\mathrm{Ba} \mathrm{LnSnO}$ materials: 25.5 ceramic substrates for high $\mathrm{T}$ superconductors," Mater. Latters, vol. 47, no. 4-5, pp. 194-198, 2001.

[38] K. Binnemans, "Interpretation of europium(III) spectra," Coord. Chem. Rev., vol. 295, pp. 1-45, Jul. 2015.

[39] K. H. Hellwege and H. G. Kahle, "Spektrum und Struktur kristalliner Europiumsalze. I. Europiumchlorid EuCI2. 6 H2O.," Zeitschrift f Phys., vol. 129, no. 1, pp. 62-84, Jan. 1951.

[40] K. H. Hellwege and H. G. Kahle, "Spectrum and structure of crystalline europium salts II. Europium bromat Eu (BrO 3 ) 3 · 9H 2 O," Zeitschrift f Phys., vol. 129, no. 1, pp. 85-103, Jan. 1951.

[41] K. Binnemans, K. Van Herck, and C. Görller-Walrand, "Influence of dipicolinate ligands on the spectroscopic properties of europium(III) in solution," Chem. Phys. Lett., vol. 266, no. 3-4, pp. 297-302, Feb. 1997.

[42] O. Laporte and W. F. Meggers, "Some Rules of Spectral Structure," J. Opt. Soc. Am., vol. 11, no. 5, p. 459, Nov. 1925.

[43] P. Dorenbos, "5d -level energies of $\mathrm{Ce} 3+$ and the crystalline environment. I. Fluoride compounds," Phys. Rev. B, vol. 62, no. 23, pp. 15640-15649, Dec. 2000.

[44] P. Dorenbos, "Systematic behaviour in trivalent lanthanide charge transfer energies," J. Phys. Condens. Matter, vol. 15, no. 49, pp. 8417-8434, Dec. 2003.

[45] P. Dorenbos, "The Eu3 + charge transfer energy andthe relation with the band gap of compounds," J. Lumin., vol. 111, no. 1-2, pp. 89-104, Jan. 2005.

[46] X. Y. Chen and G. K. Liu, "The standard and anomalous crystal-field spectra of 
Eu3+," J. Solid State Chem., vol. 178, no. 2, pp. 419-428, Feb. 2005.

[47] R. Rajaramakrishna, P. Nijapai, P. Kidkhunthod, H. J. Kim, J. Kaewkhao, and Y. Ruangtaweep, "Molecular dynamics simulation and luminescence properties of Eu3+ doped molybdenum gadolinium borate glasses for red emission," J. Alloys Compd., vol. 813, p. 151914, Jan. 2020.

[48] S. Som, A. Choubey, and S. K. Sharma, "Spectral and trapping parameters of Eu 3+ in Gd 2 O 2 S nanophosphor,” J. Exp. Nanosci., vol. 10, no. 5, pp. 350-370, Mar. 2015.

[49] N. Pathak, S. Mukherjee, D. Das, D. Dutta, S. Dash, and R. M. Kadam, "Evolution of different defect clusters in $\mathrm{Eu} 3+$ doped $\mathrm{KMgF} 3$ and $\mathrm{Eu} 3+, \mathrm{Li}+$ co-doped $\mathrm{KMgF} 3$ compounds and the immediate impact on the phosphor characteristics," J. Mater. Chem. C, 2020.

[50] Y. Shimada, H. Kiyama, and Y. Tokura, "Magnetoelectric emission in rare-earth doped ferroelectric crystals La2Ti2O7 :R3+(R=Er, Eu, and Nd)," Phys. Rev. B, vol. 75, no. 24, p. 245125, Jun. 2007.

[51] G. B. F. Bosco and L. R. Tessler, "Crystal field parameters of the C2 site in Eu2O3," Opt. Mater. X, vol. 2, p. 100028, May 2019.

[52] X. Zhao et al., "Efficient red phosphor double-perovskite Ca3WO6 with A-site substitution of Eu3+," Dalt. Trans., vol. 42, no. 37, p. 13502, 2013.

[53] X. Zhao, Y. Ding, Z. Li, T. Yu, and Z. Zou, "An efficient charge compensated red phosphor Sr3WO6: K+, Eu3+- For white LEDs," J. Alloys Compd., vol. 553, pp. 221-224, Mar. 2013.

[54] S. Zhang, Y. Hu, L. Chen, X. Wang, G. Ju, and Y. Fan, "Photoluminescence properties of Ca3 WO6:Eu3+ red phosphor,” J. Lumin., vol. 142, pp. 116-121, Oct. 2013.

[55] K. V. Dabre, K. Park, and S. J. Dhoble, "Synthesis and photoluminescence properties of microcrystalline Sr 2 ZnWO 6 :RE 3+ (RE = Eu, Dy, Sm and Pr) phosphors," J. Alloys Compd., vol. 617, pp. 129-134, Dec. 2014.

[56] A. Fu et al., "A novel double perovskite La2ZnTiO6:Eu3+ red phosphor for solid-state lighting: Synthesis and optimum luminescence," Opt. Laser Technol., vol. 96, pp. 4349, Nov. 2017.

[57] Y. Zhang, J. Xu, Q. Cui, and B. Yang, "Eu3+-doped Bi4Si3O12 red phosphor for solid state lighting: microwave synthesis, characterization, photoluminescence properties and thermal quenching mechanisms," Sci. Rep., vol. 7, no. 1, p. 42464, Mar. 2017.

[58] Y. Gao et al., "Tb 3+ and Eu 3+ co-doped Ba 6 Bi 9 B 79 O 138 : color-tunable 
phosphors by utilizing the host-sensitization effect of $\mathrm{Bi} 3+$ and enhancement of red emission upon heating," New J. Chem., vol. 41, no. 5, pp. 2037-2045, 2017.

[59] A. Katelnikovas, H. Winkler, A. Kareiva, and T. Jüstel, "Synthesis and optical properties of green to orange tunable garnet phosphors for pcLEDs," Opt. Mater. (Amst)., vol. 33, no. 7, pp. 992-995, May 2011. 
Figures

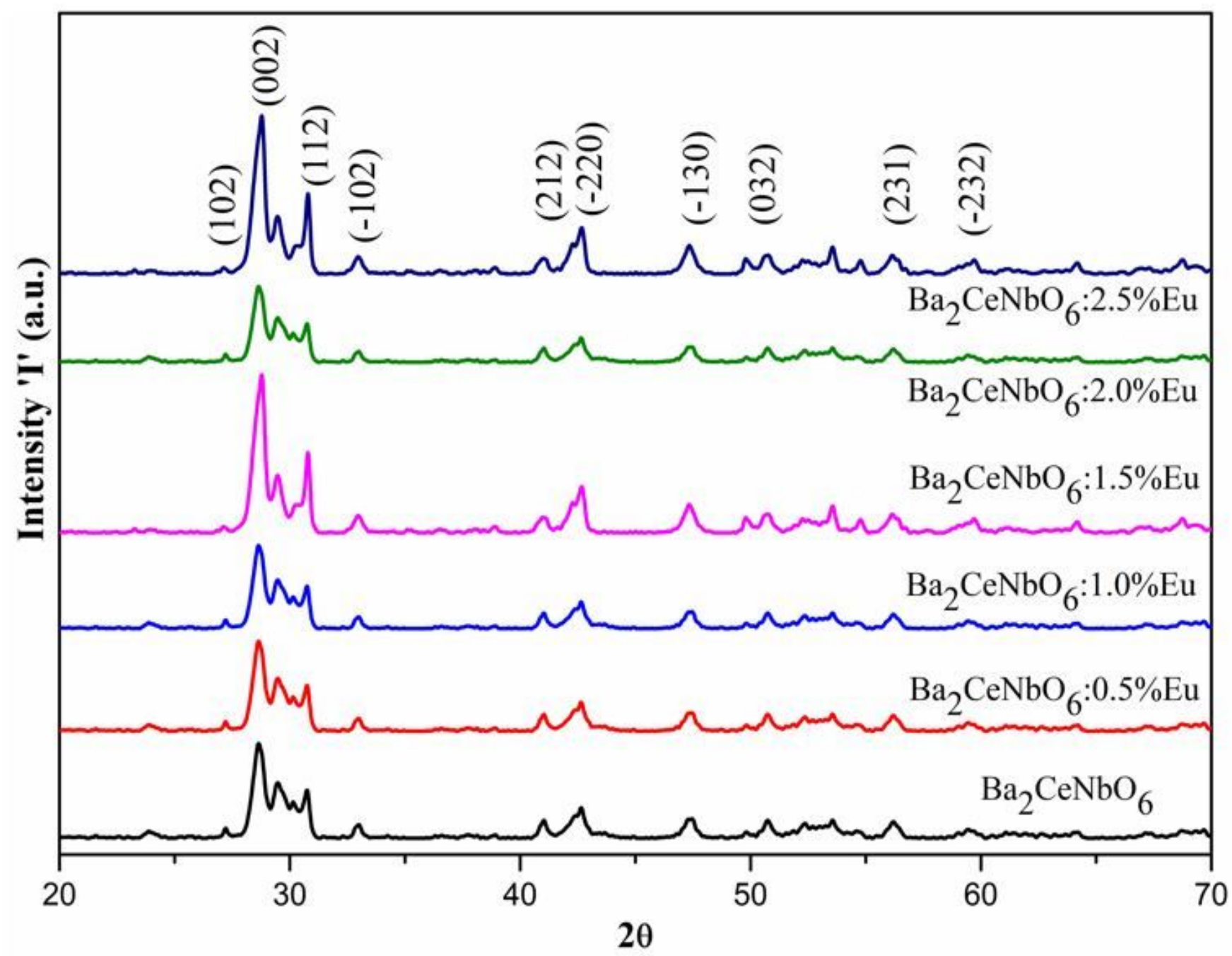

Figure 1

X-ray diffraction pattern of undoped and $\mathrm{Eu}(\mathrm{III})$ doped $\mathrm{Ba} 2 \mathrm{CeNbO6}$. 

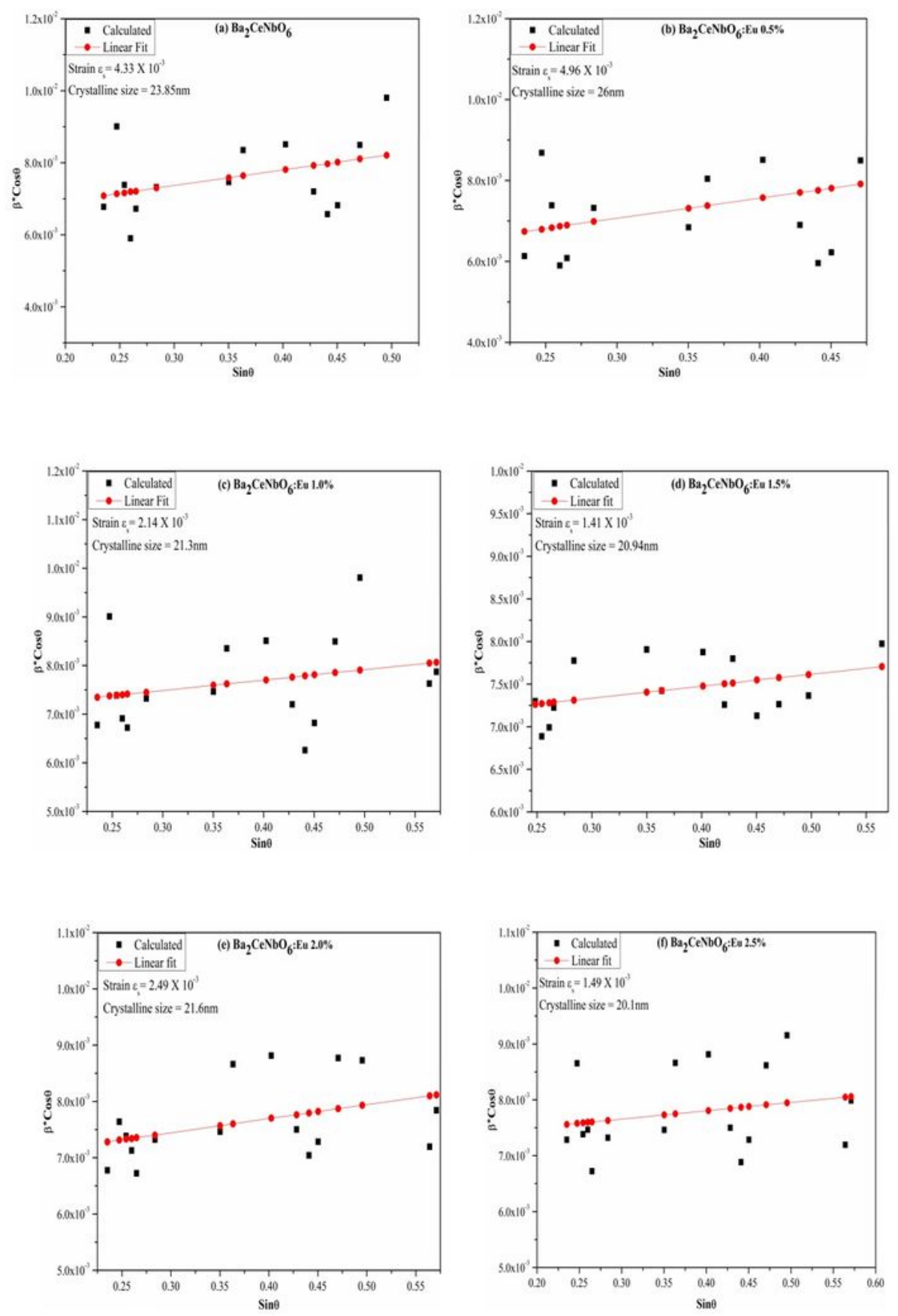

Figure 2

(a-f) Williomson-Hall plot of undoped and Eu(III) doped Ba2CeNbO6 


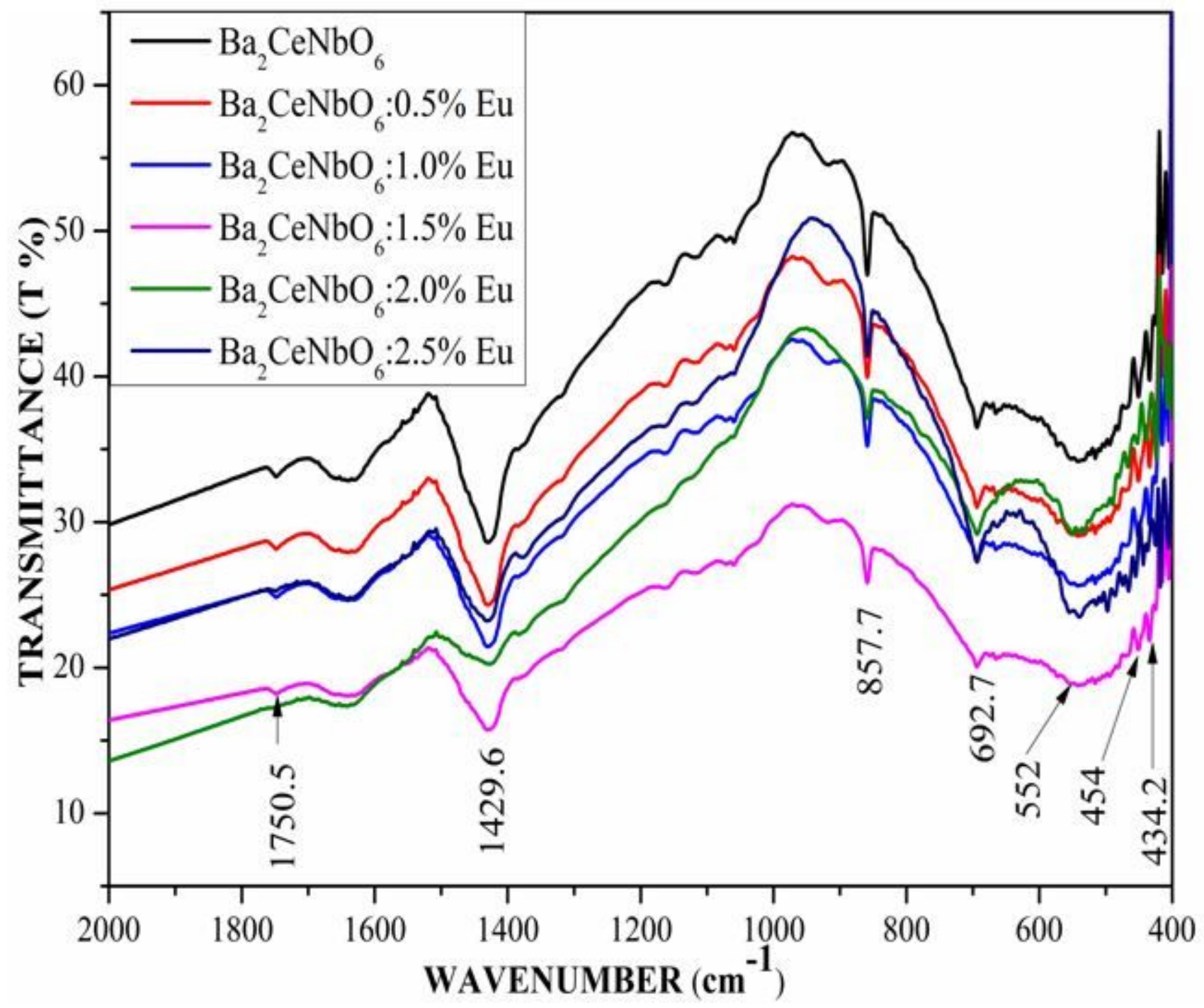

Figure 3

FTIR spectra of undoped and Eu(III) doped Ba2CeNbO6. 


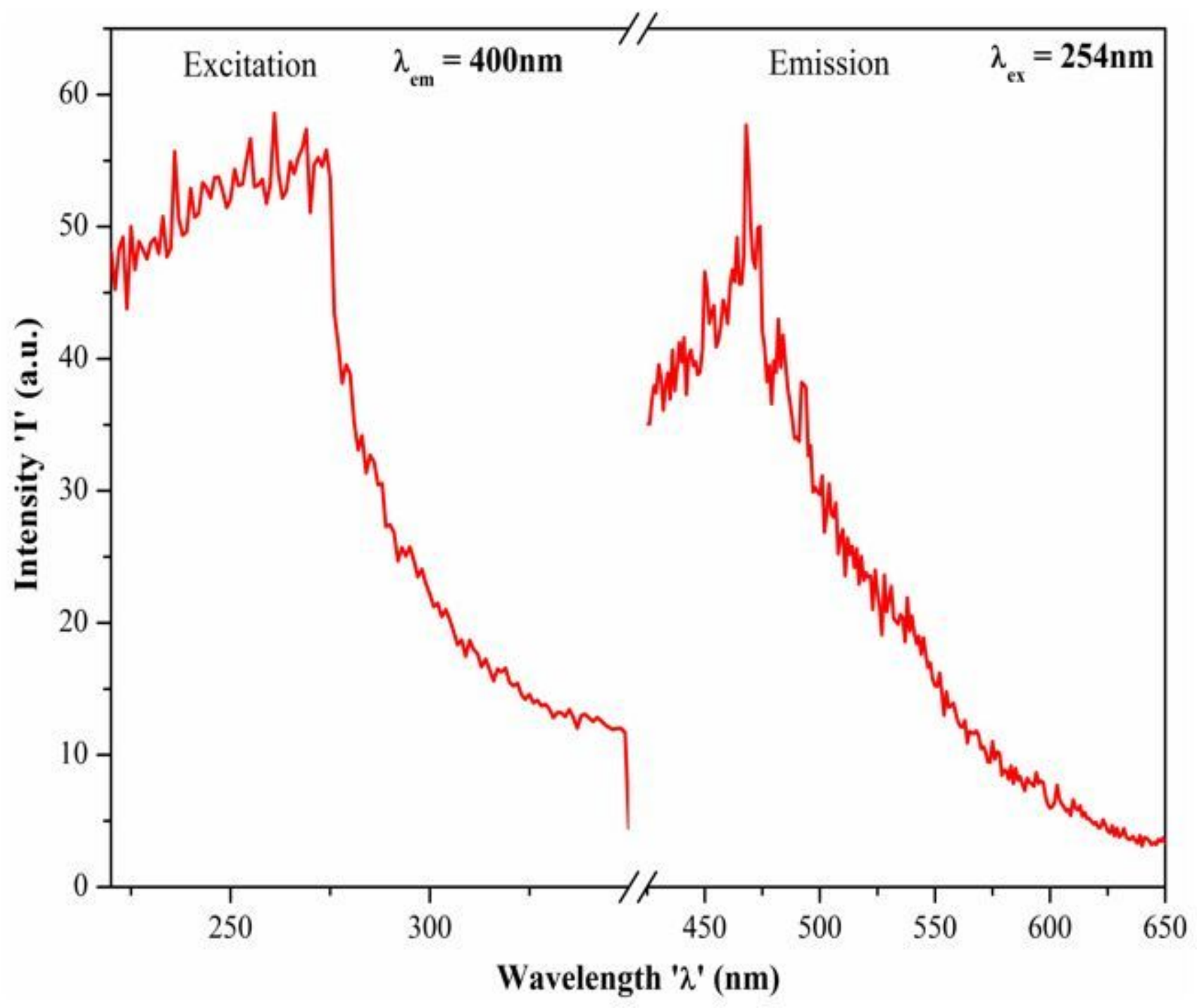

Figure 4

Photoluminescence spectra of $\mathrm{Ba} 2 \mathrm{CeNbO6.}$ 


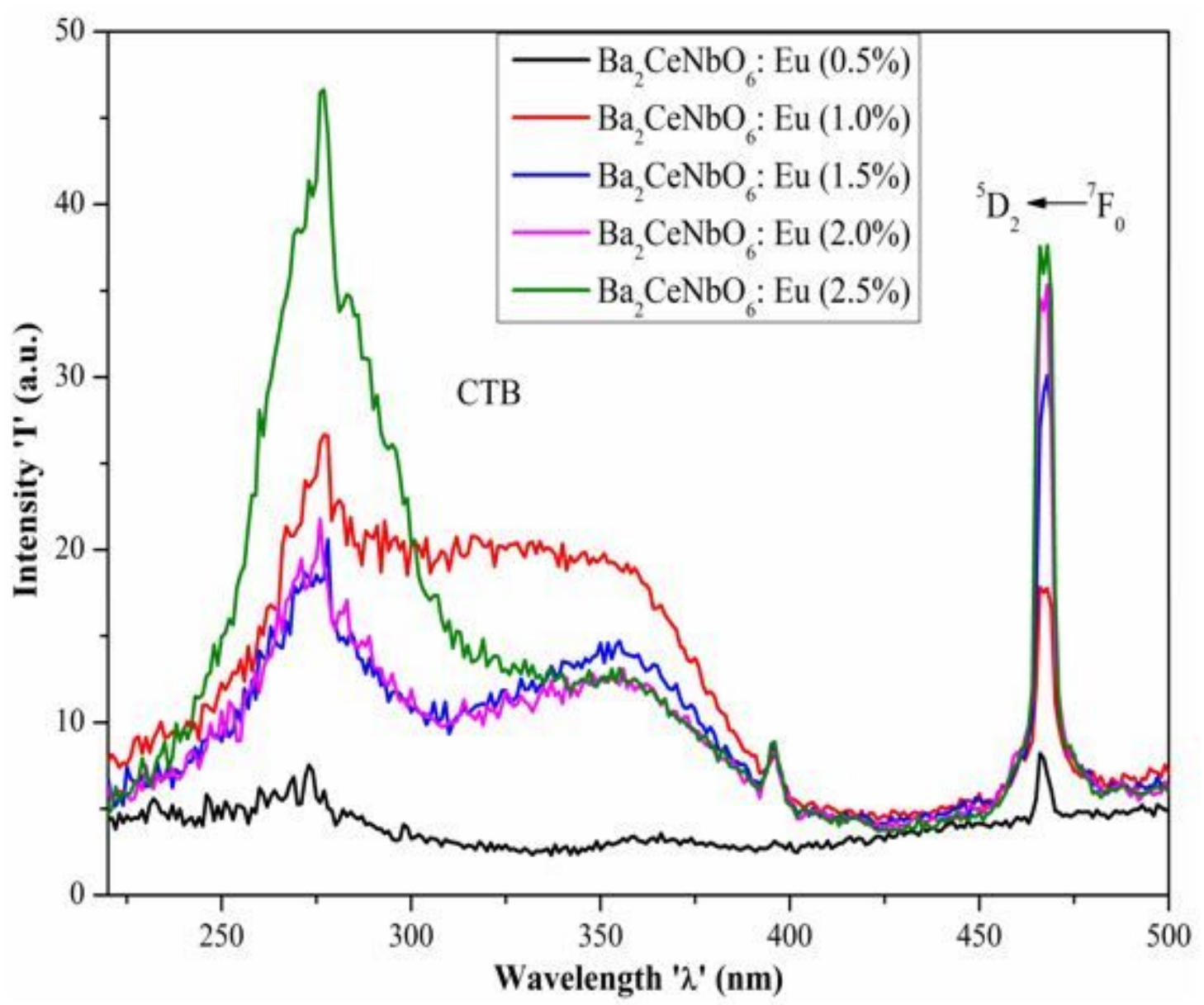

Figure 5

Photoluminescence Excitation spectra of Eu(III) doped Ba2CeNbO6 

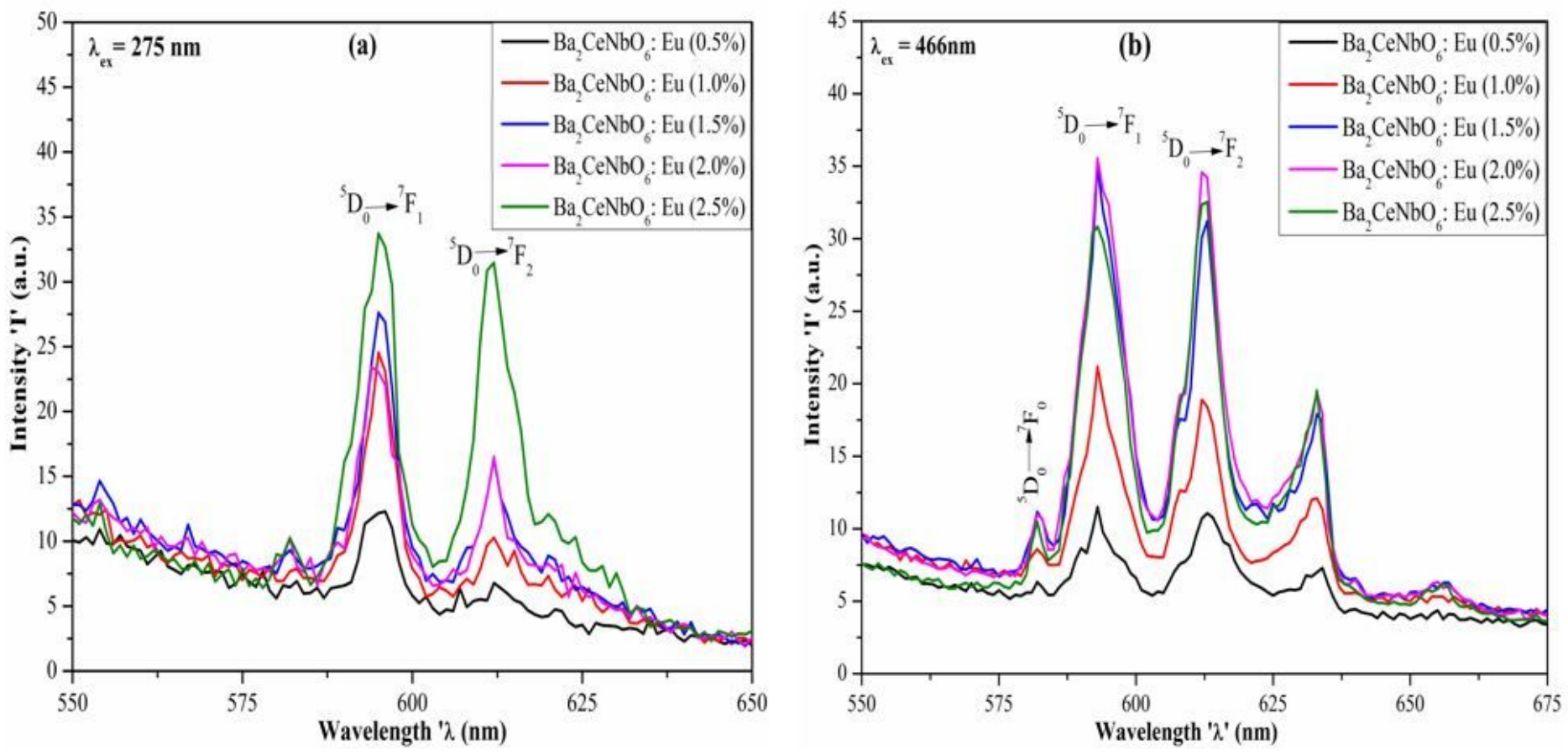

Figure 6

Photoluminescence emission spectra of Eu(III) doped Ba2CeNb06 with excitation wavelengths (a) $275 \mathrm{~nm}$ and (b) $466 \mathrm{~nm}$.
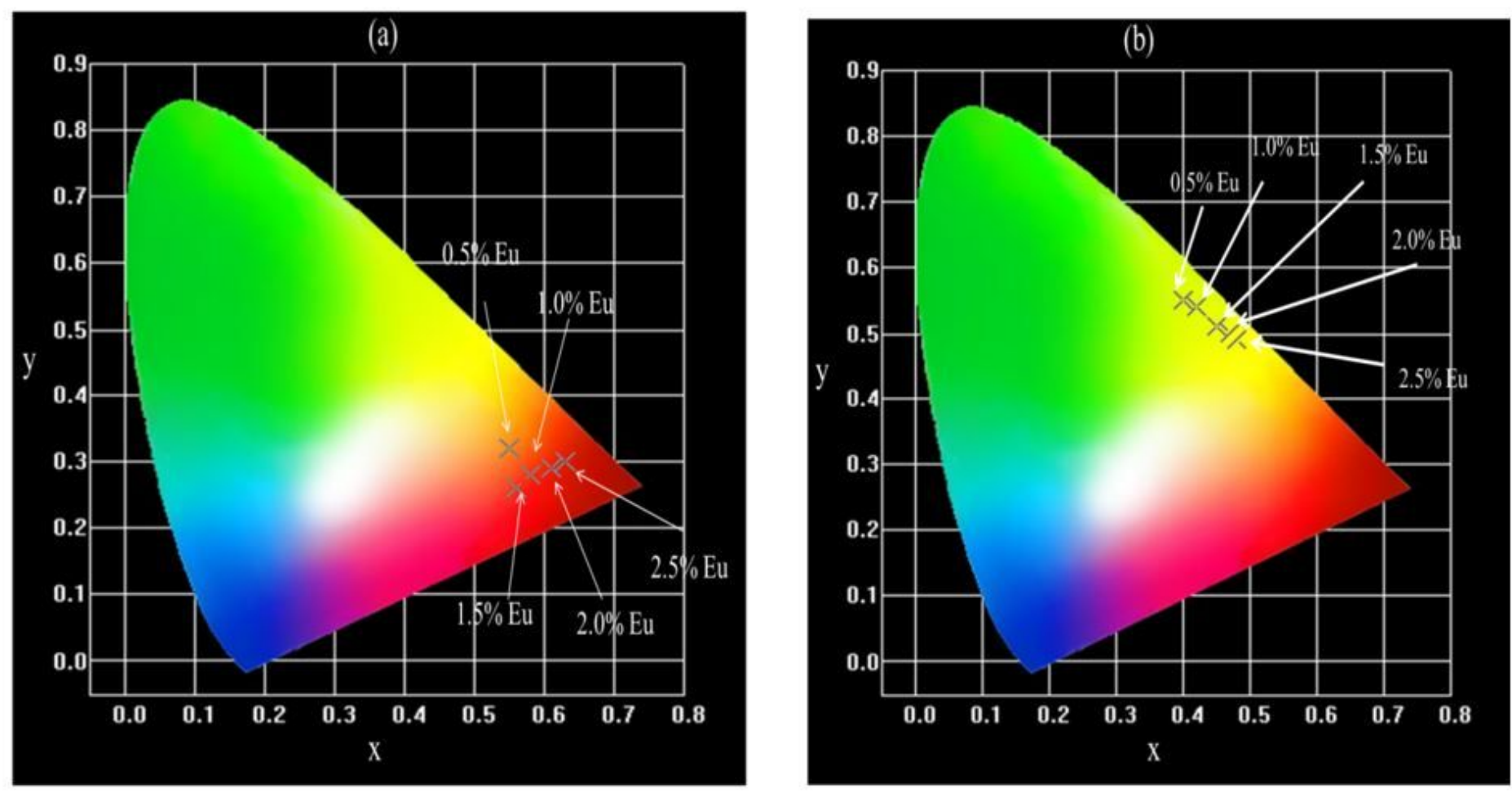

Figure 7 
CIE diagram of Eu(III) doped Ba2CeNbO6 emission at (a) $275 \mathrm{~nm}$ and (b) $466 \mathrm{~nm}$. 